Discussion Paper No. 11-037

\title{
Fiscal Stimulus and
} Distortionary Taxation

Thorsten Drautzburg and Harald Uhlig

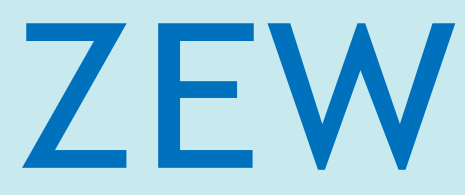

Zentrum für Europäische Wirtschaftsforschung $\mathrm{GmbH}$ Centre for European Economic Research 
Discussion Paper No. 11-037

\section{Fiscal Stimulus and Distortionary Taxation}

Thorsten Drautzburg and Harald Uhlig

Download this ZEW Discussion Paper from our ftp server:

http://ftp.zew.de/pub/zew-docs/dp/dp11037.pdf

Die Discussion Papers dienen einer möglichst schnellen Verbreitung von neueren Forschungsarbeiten des ZEW. Die Beiträge liegen in alleiniger Verantwortung der Autoren und stellen nicht notwendigerweise die Meinung des ZEW dar.

Discussion Papers are intended to make results of ZEW research promptly available to other economists in order to encourage discussion and suggestions for revisions. The authors are solely responsible for the contents which do not necessarily represent the opinion of the ZEW. 


\begin{abstract}
We quantify the fiscal multipliers in response to the American Recovery and Reinvestment Act (ARRA) of 2009. We extend the benchmark Smets-Wouters (Smets and Wouters, 2007) New Keynesian model, allowing for credit-constrained households, the zero lower bound, government capital and distortionary taxation. The posterior yields modestly positive short-run multipliers around 0.52 and modestly negative long-run multipliers around -0.42 . The multiplier is sensitive to the fraction of transfers given to credit-constrained households, the duration of the zero lower bound and the capital. The stimulus results in negative welfare effects for unconstrained agents. The constrained agents gain, if they discount the future substantially.
\end{abstract}

Keywords: Fiscal Stimulus, New Keynesian model, liquidity trap, zero lower bound, fiscal multiplier

JEL codes: E62, E63, E65, H20, H62 


\title{
Fiscal Stimulus and Distortionary Taxation*
}

\author{
Thorsten Drautzburg and Harald Uhlig ${ }^{\dagger}$ \\ University of Chicago.
}

First draft: January 2nd, 2010

This revision: May 30, 2011

*This research has been supported by the NSF grant SES-0922550.

${ }^{\dagger}$ Address: Thorsten Drautzburg and Harald Uhlig, Department of Economics, University of Chicago, 1126 East 59th Street, Chicago, IL 60637, U.S.A, email: tdrautzburg@uchicago.edu and huhlig@uchicago.edu. Additional affiliations for H. Uhlig: CentER, NBER and CEPR. We are grateful to the useful feedback from a number of seminar and conference audiences. 
"Fiscal Stimulus", the size of "fiscal multipliers" and the impact of discretionary fiscal spending on GDP and unemployment, has once again become central to policy debates in wake of the financial crisis of 2008 and fiscal policy responses in a number of countries. In this paper, we therefore seek to quantify the size, uncertainty and sensitivity of fiscal multipliers in response to a "fiscal stimulus" as in the American Recovery and Reinvestment Act (ARRA) of 2009 in the United States, using an extension of a benchmark New Keynesian model.

From a purists' perspective, this may be the wrong question to ask. Policy should care about welfare, rather than derivative measures such as GDP or unemployment. Moreover, it should seek to solve a Mirrlees-Ramsey problem, and use the best combinations of available tools and taxes to maximize welfare, subject to constraints imposed by markets and the asymmetry of information. We do not disagree. Indeed, there is a considerable literature on these topics. We address welfare issues in section 3.9, but they are not the main focus of this paper.

Indeed, many public debates focus on the effects of fiscal spending on GDP and unemployment. Economists have the tools to answer these questions, and therefore, perhaps they should. Several recent papers have addressed these issues. This paper seeks to make a contribution to this emerging literature. In essence, we seek to understand how much of the rather negative perspective on long-run multipliers in Uhlig (2010b), due to distortionary taxation in a neoclassical growth model, survives in a model that takes a very Keynesian perspective. In a nutshell, the answer is: while the benchmark long-run multiplier is now modestly negative rather than substantially negative and while the precise answer is sensitive to some key assumptions and uncertain parameters, much survives indeed.

We view the following elements as important. First, "fiscal stimulus" takes time in practice, despite calls for immediate actions as in e.g. Spilimbergo et al. (2008). The American Recovery and Reinvestment Act or ARRA (2009) therefore serves as a useful benchmark and example for the speed at which fiscal policy tools can be deployed, as emphasized by Cogan et al. 
(2010). Second, government expenditures are financed eventually with distortionary taxes, creating costly disincentive effects, a point emphasized by Uhlig (2010b). Third, monetary policy and its restrictions due to the zero lower bound (ZLB) on interest rates can matter substantially for the effectiveness of "fiscal stimulus", as emphasized by Eggertsson (2010) as well as Christiano et al. (2009), in particular if there are sticky prices and wages. Fourth, transfers are a substantial part of the ARRA and similar programs: the degree to which they are given to credit-constrained households may matter considerably, see Coenen et al. (2010). Finally, model coefficients are uncertain and results are sensitive to specific assumptions. For that reason, we use a reasonably tractable "small-scale" model rather than a larger "black box", employing Bayesian estimation techniques as well as sensitivity analysis to quantify the uncertainty in our answers. As Leeper et al. (2011) have pointed out, the New Keynesian model employed here together with its prior already are already an important determinant of our answers. This is desirable: the model assumptions should be crucial. The Bayesian estimation serves to quantify the results more sharply and to inform us about the overall posterior uncertainty.

The analysis here has much in common and is inspired by Cogan et al. (2010), but there are a number of important differences. Like them, we start from the benchmark Smets-Wouters Smets and Wouters (2007) New Keynesian model and analyze the impact of the ARRA. In contrast to these authors, we allow for a government raising revenues with distortionary taxation, and we introduce credit-constrained consumers in our benchmark model.

This analysis postulates the presence of the ZLB, either with a deterministic or endogenized duration. However, Correia et al. (2010) have shown that when consumption tax rates are a policy instrument, adjusting tax rates can substitute for adjusting interest rates, thereby circumventing the ZLB. Since we only consider various kinds of government spending as policy instruments and treat taxes as determined by different feedback rules and exogenous shocks, we neglect this potentially important channel of fiscal policy here.

We distinguish between short-run and long-run multipliers. For a bench- 
mark parameterization, we find modestly positive short-run multipliers with a posterior mean of 0.51 and modestly negative long-run multipliers centered around -0.42 . The multiplier is particularly sensitive to the fraction of transfers given to rule-of-thumb consumers, is sensitive to the anticipated length of the zero lower bound, is sensitive to the capital share and is nonlinear in the degree of price and wage stickiness. Reasonable specifications are consistent with substantially negative short-run multipliers within a short time frame.

We compute the welfare effects of the policy intervention separately for both types of agents. The effects on unconstrained agents are significantly negative but small as they are close to their unconstrained optimum. As credit-constrained agents exhibit a higher rate of time-preference, we consider a range of rates of time preference, up to $30 \%$ higher than that of unconstrained agents on an annual basis. If agents are not too impatient, the welfare gains through higher short-run consumption are more than offset by the disutility of hours worked and lower consumption in the transition back to the balanced growth path. However, starting at rates of time preference about $20 \%$ higher than that of unconstrained agents, the welfare effects can become significantly positive for constrained agents.

These models have also been criticized considerably for the lack of a financial sector, a feature likely for understanding the events of 2008 (see Uhlig, 2010a; Krugman, 2009; Buiter, 2009). We agree with this critique and therefore feature a financial friction per the "short cut" of allowing for time-varying wedges between the central bank interest rate, government bond rates and the return to private capital, following Hall (2010). Our estimates show that these wedges are indeed the key to understanding the recession of 2007 to 2009. Understanding their nature more deeply should therefore be high on the research agenda, but is not the focus of this paper and beyond its scope. An interesting explanation has been forwarded by Ilut and Schneider (2011): increases in ambiguity in markets may result in increased wedges between safe and risky assets.

Aside from the contributions cited above, the analysis here is related to 
a number of additional important contributions, notably Erceg and Linde (2010) as well as Leeper and various co-authors (Davig and Leeper, 2009; Leeper et al., 2010, 2009). In a model which also features distortionary taxes, rule of thumb consumers, and financial frictions, Erceg and Linde (2010) point out that the marginal multiplier differs from the average multiplier: If the stimulus is successful, the economy leaves the binding ZLB earlier and the effect of additional spending is reduced. We address this issue by endogenizing the duration of the ZLB in robustness tests. A key difference is their focus on the short-run when the effects of adjusting distortionary taxes instead of transfers matter less. Leeper et al. (2010) allow future government consumption and transfers to adjust in order to rebalance the government budget, and find that adjusting spending and component in addition to taxes raises the multiplier. Leeper et al. (2009) point out the importance of productive government investment and government capital, Davig and Leeper (2009) allow for fiscal policy to switch between passive and active regimes in a New Keynesian model. Interestingly, they find the largest difference in multipliers due to switches in the monetary policy regime, which we address by varying the ZLB duration.

The paper is structured as follows. Section 1 gives an overview of the model. Section 2 discusses the estimation and calibration procedure. It provides a decomposition of the shocks driving the 2007-2009 recession, and shows that financial frictions have been key, in stark contrast to the fullsample variance decomposition. Both sections are complemented by a detailed technical appendix which provides all model details as well as code for replicating our results or calculating other fiscal experiments. Section 3 presents the main results on the fiscal multiplier. It provides a sensitivity analysis which highlights the main driving forces behind our results. In addition, it provides a discussion of the welfare effects of the stimulus package. Section 4 concludes. 


\section{The model}

The model is an extension of Smets and Wouters (2007), and we shall refer the reader to that paper as well as to the technical appendix for the complete details. Here we shall provide a brief overview as well as describe the extensions.

The Smets and Wouters (2007) model is a New Keynesian model, set in discrete time. There is a continuum of households. Workers supply homogeneous labor in monopolistic competition. Unions differentiate the labor supplied by households and set wages for each type of labor. Wages are Calvo-sticky. There is a continuum of intermediate good firms. They supply intermediate goods in monopolistic competition. They set prices. Prices are Calvo-sticky. Final goods use intermediate goods. Final goods are produced in perfect competition. Households have preferences for final goods, allowing for habit formation, as well as leisure. Capital is produced with investment in the form of the final good, but there are adjustment costs to investment: given installed capital and previous-period investment, the marginal product of investment for producing new capital is decreasing. There is variable capital utilization.

We extend the model with several features. Briefly, we constrain the interest rate set by the central bank to be nonnegative. We let the government raise revenues with distortionary taxation. We introduce credit-constrained consumers. We feature government capital. We introduce a wedge between various returns, as a stand-in for financial frictions. We adopt the notation convention that variables indexed $t$ are known in period $t$.

\subsection{The zero lower bound}

More precisely, the monetary authority follows a Taylor-type rule, but interest rates may be held constant for a deterministic period of time or are modelled to be bounded below by a constant slightly above zero. It is easier to describe these scenarios it in their log-linearized form: for the original version, the reader is referred to the technical appendix. 
In our benchmark scenario, the central bank keeps the interest rate at its historical level of 2008:4 for $k$ quarters. Households fully anticipate this policy. Let $\hat{R}_{t}^{T R}$ denote the log-deviation of the shadow Taylor Rule return, given by:

$$
\begin{aligned}
\hat{R}_{t}^{T R}=\psi_{1}(1- & \left.\rho_{R}\right) \hat{\pi}_{t}+\psi_{2}\left(1-\rho_{r}\right)\left(\hat{y}_{t}-\hat{y}_{t}^{f}\right) \\
& +\psi_{3} \Delta\left(\hat{y}_{t}-\hat{y}_{t}^{f}\right)+\rho_{R} \hat{R}_{t-1}^{T R}+m s_{t}
\end{aligned}
$$

where $\hat{\pi}_{t}$ is the log-deviation for inflation, $\hat{y}_{t}$ is the log-deviation for output, $\hat{y}_{t}^{f}$ is the log-deviation in the flexible-price version of the economy and $m s_{t}$ is a shock to the interest rate set by the central bank.

The effective interest rate in our benchmark scenario is then given by:

$$
\hat{R}_{t}^{F F R}=\left(1-Z L B_{t}\right) \hat{R}_{t}^{T R}+Z L B_{t} \hat{R}_{0}^{F F R}
$$

where $Z L B_{t}$ is an indicator function modelling which takes the value of one while the ZLB lasts and zero otherwise. During the ZLB, the central bank return equals its historical starting value, $\hat{R}_{0}^{F F R}$.

When endogenizing the ZLB duration, the central bank sets the logdeviation of the central bank return to

$$
\hat{R}_{t}^{F F R}=\max \left\{-\left(1-\bar{R}^{F F R}\right)+\bar{\epsilon}, \hat{R}_{t}^{T R}\right\}
$$

where $\bar{R}^{F F R}$ is the steady state nominal return, $\bar{\epsilon}>0$ is a constant set slightly above zero for technical reasons (and set to $\bar{\epsilon}=\frac{0.25}{400}$ in the numerical calculations, implying a lower bound of 25 basis points for the central bank interest rate).

\subsection{Households, distortionary taxation and financial frictions.}

A fraction $1-\phi$ of the household is unconstrained and solves an infinitehorizon maximization problem. The preferences of such a household $j$ are 
given by

$$
U=\mathbb{E}\left[\sum_{t=0}^{\infty} \beta^{s}\left(\frac{1}{1-\sigma}\left(c_{t}(j)-h c_{t-1}^{\text {aggr }}\right)^{1-\sigma}\right) \exp \left(\frac{\sigma-1}{1+\nu} n_{t}(j)^{1+\nu}\right)\right]
$$

where $c_{t}(j)$ is consumption of household $j, n_{t}(j)$ is its labor supply and $c_{t}^{\text {aggr }}$ is aggregate consumption. $h \in[0,1)$ captures external habit formation, $\sigma$ denotes the inverse of the intertemporal elasticity of substitution, and $\nu$ equals the inverse of the labor supply elasticity. Households discount the future by $\beta \in(0,1)$.

Following Trabandt and Uhlig (2010), we assume that the government provides transfers and collects linear taxes on labor income, capital income net of depreciation as well as consumption, adapted to the model here. The budget constraint of household $j$ is therefore given by

$$
\begin{aligned}
(1+ & \left.\tau^{c}\right) c_{t}(j)+x_{t}(j)+\frac{B_{t}^{n}(j)}{R_{t}^{g o v} P_{t}} \\
\leq & s_{t}^{\text {unconstr }}+\frac{B_{t-1}^{n}(j)}{P_{t}}+\left(1-\tau_{t}^{n}\right) \frac{W_{t}}{P_{t}}\left(n_{t}(j)+\lambda_{w, t} n_{t}^{(\operatorname{aggr})}\right)+ \\
& \quad+\left(\left(1-\tau^{k}\right)\left(\frac{R_{t}^{k} u_{t}(j)}{P_{t}}-a\left(u_{t}(j)\right)\right)+\delta \tau^{k}\right)\left(\left(1-\omega_{t-1}^{k}\right) k_{t-1}^{p}(j)+\omega_{t-1}^{k} k_{t-1}^{p, a g g r}\right)+\frac{\Pi_{t}^{p}}{P_{t}},
\end{aligned}
$$

and the capital accumulation constraint is given by

$$
k_{t}^{p}(j)=\frac{(1-\delta)}{\mu} k_{t-1}^{p}(j)+q_{t+s}^{x}\left(1-\xi\left(\frac{x_{t}(j)}{x_{t-1}(j)}\right)\right) x_{t}(j),
$$

where $c_{t}(j)$ is consumption, $x_{t}(j)$ is investment, $B_{t-1}^{n}(j)$ are nominal government bond holdings, $n_{t}(j)$ is labor, $k_{t-1}^{p}(j)$ is private capital, and $u_{t}(j)$ is capacity utilization, all of household $j$ and chosen by household $j$. $R_{t}^{\text {gov }}$ is the nominal return for the one-period government bond from $t$ to $t+1$ set at date $t, n_{t}^{(\operatorname{aggr})}$ is aggregate labor, $P_{t}$ is the aggregate price level, $W_{t}$ is aggregate wages, $\lambda_{w, t}$ is the aggregate mark-up from union-determined wages, $R_{t}^{k}$ is the undistorted return on capital and $\omega_{t}^{k}$ is a friction or wedge on private capital markets. In the budget constraint, note that it enters as a variable 
known at date $t-1$, so that the distortions to future capital returns impacts on investment in the current period. Also note that the individual losses due to this wedge are redistributed in the aggregate, so that the wedge distorts investment decisions, but does not destroy aggregate resources directly. $\Pi_{t}^{p}$ are nominal firm profits, $q_{t+s}^{x}$ is an investment-specific technology parameter, $\xi(\cdot)$ are adjustment costs, satisfying $\xi(\mu)=\xi^{\prime}(\mu)=0, \xi^{\prime \prime}>0, \tau^{c}, \tau^{n}, \tau^{k}$ are taxes and $s_{t}^{\text {unconstr }}$ are real transfers to unconstrained households, all taken as given by household $j$, and $a(\cdot)$ represents the strictly increasing and strictly convex cost function of varying capacity utilization. In particular, note that taxing capital net of depreciation implies deducting a depreciation rate that depends on capacity utilization. Furthermore, the household receives labor income both directly from working as well as indirectly from the surplus that unions charge on labor: both sources of labor income are taxed.

We assume that the interest rate $R_{t}^{\text {gov }}$ on government bonds, which unconstrained households can freely trade, equals the federal funds rate $R_{t}^{F F R}$ up to an exogenous friction or wedge $\omega_{t}^{g o v}$ :

$$
R_{t}^{g o v}=\left(1+\omega_{t}^{g o v}\right) R_{t}^{F F R}
$$

In difference to Smets and Wouters (2007), the discount factor $\beta$ of the households is not subject to shocks. Rather, we focus on the wedges $\omega_{t}^{k}$ and $\omega_{t}^{g o v}$ on financial markets as part of the household budget constraint.

We assume that a fraction $\phi \in(0,0.5)$ of the households is credit-constrained. In their version of the budget constraint, $B_{t-1}^{n}(j)=0, x_{t}(j)=0$ and $k_{t-1}^{p}(j)=0$, i.e. these households do not save or borrow. They do receive profit income from intermediate producers (which equals zero in the steady state). Put differently, the budget constraint of a credit-constrained household $j$ is

$$
\begin{aligned}
& \left(1+\tau^{c}\right) c_{t}(j) \\
& \leq s_{t}^{\text {constr }}+\left(1-\tau_{t}^{n}\right) \frac{W_{t}}{P_{t}}\left(n_{t}(j)+\lambda_{w, t} n_{t}^{(\operatorname{aggr})}\right)+\frac{\Pi_{t}^{p}}{P_{t}}
\end{aligned}
$$


where $s_{t}^{\text {constr }}$ are the transfers to credit-constrained agents. As a justification, one may suppose that credit-constrained discount the future substantially more steeply, and are thus uninterested in accumulating government bonds or private capital, unless their returns are extraordinarily high. Conversely, these households find it easy to default on any loans, and are therefore not able to borrow. We hold the identity of credit-constrained households and thereby their fraction of the total population constant. Note that we allow the transfers $s_{t}^{\text {constr }}$ to constrained households to differ from the transfers $s_{t}^{\text {unconstr }}$ to the unconstrained households.

Wages are set by unions on behalf of the households, recognizing that each differentiated wage is Calvo-sticky. Since workers of the unconstrained households represent the majority in these unions, wages are set according to their preferences. Firms hire workers randomly from both types of households, so that labor supplied by both types of households is the same in equilibrium.

\subsection{Government capital and policy feedback rules}

As the ARRA contains a government investment, we wish to feature government capital as productive input. We also wish to keep the final goods production function to have constant returns to scale on the firm level, in order to maintain the assumption of perfect competition there. We therefore assume that government capital $K_{t-1}^{g}$ enters private production as an externality for the individual intermediate-goods firm, similar to the model in Barro and Sala-i Martin (1992). In order to obtain an aggregate constantreturns-to-scale production function before fixed costs, we assume that the externality of $K_{t-1}^{g}$ at the firm level is relative to aggregate output, before fixed costs.

Specifically, we assume that the technology of intermediate firm $i$ is given 
by

$$
Y_{t}(i)=\tilde{\epsilon}_{t}^{a}\left(\frac{K_{t-1}^{g}}{\int_{0}^{1} Y_{t}(\iota) d \iota+\Phi \mu^{t}}\right)^{\frac{\zeta}{1-\zeta}}\left(K_{t}^{\mathrm{efff}}(i)\right)^{\alpha}\left(\mu^{t} n_{t}(i)\right)^{1-\alpha}-\mu^{t} \Phi,
$$

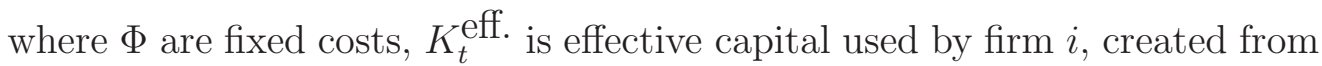
aggregate private capital,

$$
K_{t}^{\mathrm{eff}}=u_{t} k_{t-1}^{p}(1-\phi)
$$

(assuming symmetric choices for the unconstrained households), where $\epsilon_{t}^{a}$ is an exogenous, stochastic component of TFP, and where the services of government capital $K_{t-1}^{g}$ are subject to congestion: what matters is the ratio of government capital to average gross output, i.e. inclusive of the fixed costs. As a result, the aggregate production function in the absence of price dispersion is given by

$$
Y_{t}=\epsilon_{t}^{a} K_{t-1}^{g} \zeta K_{t}^{s \alpha(1-\zeta)}\left(\mu^{t} n_{t}\right)^{(1-\alpha)(1-\zeta)}-\mu^{t} \Phi, \quad \epsilon_{t}^{a} \equiv\left(\tilde{\epsilon}_{t}^{a}\right)^{1-\zeta}
$$

where TFP in terms of the private factors of production is

$$
T F P=\epsilon_{t}^{a} K_{t-1}^{g} \zeta \mu^{(1-\alpha)(1-\zeta) t}
$$

We assume that the accumulation of government capital is symmetric to the accumulation of private capital, i.e., is subject to a similar technology,

$$
k_{t}^{g}=\frac{(1-\delta)}{\mu} k_{t-1}^{g}+q_{t}^{g}\left(1-S_{g}\left(\frac{x_{t}^{g}+\epsilon_{t}^{x, g}}{x_{t-1}^{g}+\epsilon_{t-1}^{x, g}}\right)\right)\left(x_{t}^{g}+\epsilon_{t}^{x, g}\right)
$$

where $S_{g}(\mu)=S_{g}^{\prime}(\mu)=0, S_{g}^{\prime \prime}(\cdot)>0$ represent adjustment costs, $q_{t}^{x, g}$ is a shock to the government-investment-specific technology parameter, and $\epsilon_{t}^{x, g}$ is additional, exogenous government investment. We assume that the capacity utilization of government capital and therefore its depreciation is constant. We assume that the government chooses investment to maximize 
the present discounted value of output net of investment costs, except for a discretionary fiscal stimulus, denoted by $\epsilon_{t}^{x, g}$ and set to zero at steady state. Put differently, the first-order condition of the government determines optimal government investment, while actual government investment may be higher by some amount chosen along the stimulus path. To enforce the expansion of government investment, we stipulate that the government cannot undo the stimulus investment for the first twelve periods, but has to provide at least replacement for the depreciated ARRA investment - otherwise, the deviation from the optimality condition would imply complete crowding out.

We assume a feedback rule for labor tax rates as follows (for the full detail, see the technical appendix), following Uhlig (2010b). Break the period-byperiod government budget constraint in two parts. On the "right side", there is a "deficit" $d_{t}$, prior to new debt and labor taxes

$$
\begin{aligned}
d_{t}= & \text { gov.spend.+subs. }{ }_{t}+\text { old debt repaym. }_{t} \\
& \text { - cons.tax rev.,cap.tax rev }{ }_{t}-\bar{\tau}^{l} \text { lab.income }_{t}
\end{aligned}
$$

which needs to be financed on the "left side" with labor tax revenues and new debt,

$$
\tau_{t}^{l} \text { lab.income }_{t}+\text { new debt } t=d_{t}
$$

Along the balanced growth path, there is a path for the debt level as well as the deficit $\bar{d}_{t}$. The labor tax rate is then assumed to solve

$$
\left(\tau_{t}^{l}-\bar{\tau}^{l}\right) \text { lab.income }_{t}=\psi_{\tau}\left(d_{t}-\bar{d}_{t}\right)+\epsilon_{\tau, l}
$$

where $\epsilon_{\tau, l}$ is a labor tax shock.

\subsection{Shocks}

We assume that there are ten stochastic processes driving the economy. Unless stated otherwise, the processes follow independent AR(1)'s in logs: (1) Technology $\tilde{\epsilon}_{t}^{a}$, (2) Gov.bond wedge $\omega_{t}^{g o v}$ : financial friction wedge between 
FFR and gov't bonds, (3) Priv. bond wedge $\omega_{t}^{k}$ : financial friction wedge between gov't bond returns and a component of the returns to private capital, (4) Gov. spending plus net export. Co-varies with technology, (5) Investment specific technology $q_{t}^{x}$ (rel. price), (6) Gov. investment specific technology $q_{t}^{g}$ (rel. price), (7) Monetary policy $m s_{t}$, (8) Labor tax rates $\epsilon_{\tau, l}$, (9) Mark-up for prices: $\operatorname{ARMA}(1,1)$, and (10) Mark-up: wages: $\operatorname{ARMA}(1,1)$.

For the stimulus plan, we use three series, capturing the changes in transfers, government consumption and government investment. We followed the strategy of Cogan et al. (2010), but our decomposition of government spending into consumption and investment as well as the need to pay particular attention to transfers meant that we needed to reclassify the various spending categories, according to the American Recovery and Reinvestment Act (ARRA). As source, we have used the estimates by the Congressional Budget Office (CBO, 2009) for the effects of the ARRA by budget title. The annual time path for these expenditures is directly taken from the $\mathrm{CBO}$, whereas the distribution within each year is proportional to the Cogan et al. (2010) path within each year. The details on the components are contained in appendix 5.1. A graphical overview on the time path is presented in figure 1. Essentially, we decomposed their government spending path into a separate consumption and investment path, and furthermore included transfers. Most importantly, much of the transfers are "front-loaded", i.e. occur earlier than government spending, while the "stimulus" government investment occurs later.

Furthermore, we assume that the central bank will leave the federal funds rate unchanged at near zero for eight quarters, and that this is fully anticipated, as of the first quarter of 2009. For the numerical calculations, the relaxation algorithm proposed by Juillard (1996) and implemented in Dynare is particularly convenient for the type of forward-simulation (rather than estimation) performed here. By solving a potentially time-varying system of equations backward from terminal conditions, it allows to incorporate anticipated shocks even when they interact coefficients for example to "switch off" the interest rate rule temporarily. In Drautzburg and Uhlig (2011) we 
investigate whether the particular modelling and solution method we employ here to account for the ZLB may play a role for our results.

\section{Estimation and Analysis}

\subsection{Data and Estimation}

We solve the model, using a log-linear approximation and Dynare. The first-order conditions and their log-linearized versions are in a technical appendix, available up on request. We estimate the model, using the following ten time series: (1) Output: Chained 2005 real GDP, growth rates, (2) Consumption: Private consumption expenditure, growth rates, (3) Investment: private fixed investment, growth rates, (4) Government investment: growth rates, (5) Hours worked: Civilian employment index $\times$ average nonfarm business weekly hours worked index, demeaned log, (6) Inflation: GDP deflator, quarterly growth rates, (7) Wages: Nonfarm Business, hourly compensation index. Growth rates, (8) FFR: Converted to quarterly rates, (9) CorporateTreasury bond yield spread: Moody's Baa index - 10 yr Treasury bond at quarterly rates, demeaned, (10) Dallas Fed gross federal debt series at par value, demeaned $\log$.

Sources and details for the data are described in appendix 5.1. We use an updated version of the Smets-Wouters dataset, for the range 1947:2-2009:4, using quarterly data and four periods for the start-up. In difference to the original dataset, we classify consumer durables as investment expenditure. The estimation of the model uses data from 1948:2 up to 2008:4, with the additional four quarters for comparison of the model prediction to the actual evolution and the first four quarters used to presample. We choose the longer sample, as it includes the Korean war as well as the Vietnam war buildup, in contrast to the shorter Smets-Wouters sample from 1967 onwards. Figure 2 shows the additional evidence from the larger fluctuation in fiscal expenditures available in this larger sample.

We fixed ("calibrated") several parameters a priori. For tax rates and the 
This paper vs CCWT: Aggregate

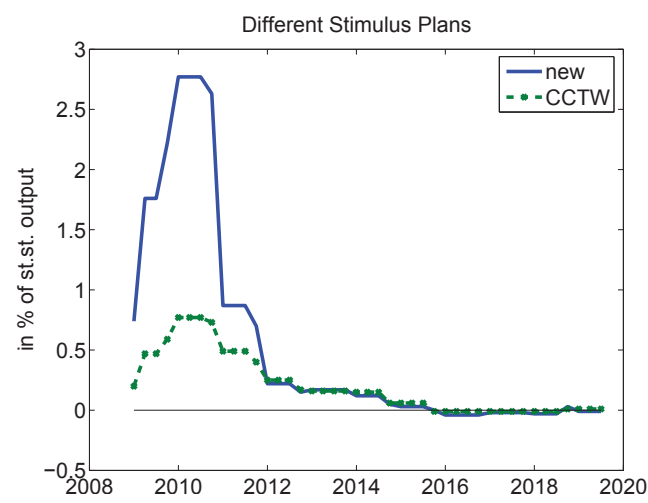

Our "stimulus" in detail

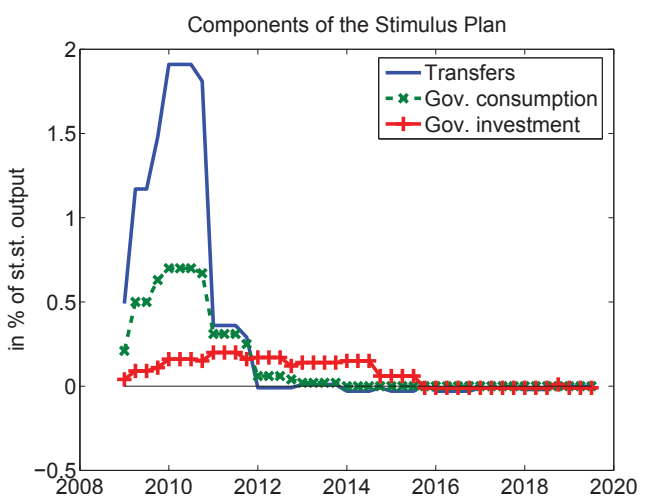

Figure 1: Our three stimulus components and their comparison to Cogan et al. (2010). Essentially, we decomposed their government spending path into a separate consumption and investment path, and furthermore included transfers.

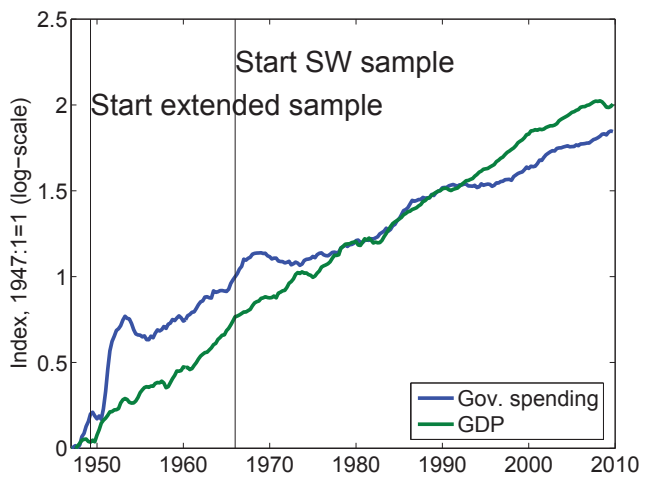

Figure 2: Comparing our extended sample to the original Smets-Wouters data set. Notice the additional variation in government spending in the larger sample. 
debt-GDP ratio, we relied on Trabandt and Uhlig (2010). Time averages of government spending components were obtained from the NIPA, Table 3.1 (quarterly), lines 35 (investment), 16 (consumption), transfers (17). Government consumption includes net exports (line 2 minus line 14 in Table 4.1). To obtain ratios relative to GDP, GDP data from line 1, Table 1.1.5 was used. Following Smets and Wouters (2007), the Kimball curvature parameter is taken from Eichenbaum and Fisher (2007), who set it to roughly match it to their data on the empirical frequency of price adjustment. Following Cooley and Prescott (1995), the depreciation rate is derived from the law of motion for capital and their observation of $\frac{\bar{x}}{k}=0.0076$ at quarterly frequency. The complete list of calibrated parameters, and their comparison to the corresponding parameters in Smets and Wouters (2007), if available, is in table 1. We estimate our model, using Dynare and a fairly standard Bayesian prior. Details on the estimation can be found in appendix 5.2. The estimates largely agree with those found by Smets and Wouters (2007), leaning somewhat more to more endogenous persistence: the habit parameter is slightly higher, as are estimates of price and wage stickiness, for example. Like these authors, our estimates also yield a rather small capital share: our posterior mean is 0.24 , while they found 0.19 . This is at odds with calibrated values in the literature, see e.g. Cooley and Prescott (1995), and may play a substantial role in calculating the long-horizon impact of distortionary taxation. We shall investigate this issue in our sensitivity analysis. The calibrated government investment-to-GDP ratio as well as the estimated growth trend $\mu \approx 1.005$ implies a government share in production of $\zeta \approx 2.30$ percent.

\subsection{Decomposing the 2007-2009 recession}

The model allows the decomposition of movements in our ten macroeconomic time series into the ten shocks that caused them. The first-order conditions of the households imply:

$1=\beta E_{t}\left[\frac{u_{c, t+1}}{u_{c, t}} \frac{R_{t}^{g o v}}{\pi_{t+1}}\right]=\beta E_{t}\left[\frac{u_{c, t+1}}{u_{c, t}}\left(1+\omega_{t}^{g o v}\right) \frac{R_{t}^{F F R}}{\pi_{t+1}}\right]$ 
Table 1: Calibrated parameters.

\begin{tabular}{l|cc} 
& SW $(1966: 1-2004: 4)$ & This paper $(1948: 2-2008: 4)$ \\
\hline Depreciation $\delta$ & 0.025 & 0.0145 \\
Wage mark-up $\lambda_{w}$ & 0.5 & 0.5 \\
Kimball curvature goods mkt. $\hat{\eta}_{p}$ & 10 & 10 \\
Kimball curvature labor mkt. $\hat{\eta}_{w}$ & 10 & 10 \\
Capital tax $\tau^{k}$ & $\mathrm{n} / \mathrm{a}$ & 0.36 \\
Consumption tax $\tau^{c}$ & $\mathrm{n} / \mathrm{a}$ & 0.05 \\
Labor tax $\tau^{n}$ & $\mathrm{n} / \mathrm{a}$ & 0.28 \\
Share credit constrained $\phi$ & $\mathrm{n} / \mathrm{a}$ & 0.25 \\
\hline Gov. spending, net exports-GDP $\frac{\bar{g}}{\bar{y}}$ & 0.18 & 0.153 \\
Gov. investment-GDP $\frac{\bar{x}^{g}}{\bar{y}}$ & $\mathrm{n} / \mathrm{a}$ & 0.04 \\
Debt-GDP $\frac{\bar{b}}{\bar{y}}$ & $\mathrm{n} / \mathrm{a}$ & $4 \times 0.63$ \\
\hline & & $Q_{t+1}$ \\
& $\beta E_{t}\left[\frac{u_{c, t+1}}{u_{c, t}}\left(\left(1-\omega_{t}^{k}\right)\left(\left(1-\tau^{k}\right)\left(r_{t+1}^{k} u_{t+1}-a\left(u_{t+1}\right)\right)+\delta \tau^{k}\right)+(1-\delta) \frac{Q_{t}}{2}\right.\right.$
\end{tabular}

where $\omega_{t}^{\text {gov }}$ is due to government bond shocks and creates a wedge between between the FFR and government bonds, while $\omega_{t}^{k}$ is due to private bond shocks, creating a wedge between government bonds and private capital. $Q_{t}$ is the price of capital. It is instructive to simplify the above expression by assuming a constant price of capital $Q_{t}$ and constant capacity utilization as well as ignoring uncertainty. Then the first line can be substituted in the second to yield:

$$
1=\frac{1}{\left(1+\omega_{t}^{g o v}\right)} \frac{\pi_{t+1}}{R_{t}^{F F R}}\left(\left(1-\omega_{t}^{k}\right)\left(r_{t+1}^{k}-\tau^{k}\left(r_{t+1}^{k}-\delta\right)\right)+(1-\delta)\right) .
$$

This equation shows that, up to a first order approximation, the wedges $\omega_{t}^{k}$ (after re-scaling) and $\omega_{t}^{b}$ both add up to the total wedge between the return on private capital net of taxes and the Federal Funds Rate $R_{t}^{F F R}$. These wedges are stand-ins for financial frictions. It is therefore interesting to examine their role for the 2007-2009 recession.

As figure 2.2 as well as table 2 document, shocks to these wedges indeed played a large role in understanding the recent recession, accounting alone for over $100 \%$ of the decline in output, in stark contrast to their small contribu- 
tion to the full-sample variance of output as well as other included time series. Figure 4 provides the impulse response to a one-standard deviation shock to these two wedges. As one can see, the government bond shock depresses output, consumption and private as well as government investment, whereas the shock to the spread between private bonds and government bonds leads to a decline in consumption only with some delay and actually increases government investments. These shocks furthermore result in a modest decline in the federal funds rate (not shown).

Since not only GDP growth but also unemployment is at the center of many public debates, we back out a predicted change in the unemployment rate from the model. To that end we regress the quarterly unemployment rate on the hours worked measure used to estimate model and use the implied OLS estimate to infer the effect on the unemployment rate. The fit is reasonable with an $R^{2}$ of 0.77 . We neglect the additional parameter uncertainty introduced because of the uncertain estimates of the regression coefficients. ${ }^{1}$

\section{Results}

Armed with our posterior estimates as well as the specification of the stimulus path, we shall now proceed to calculate the implied effects. We provide confidence bands, covering 90 percent or 67 percent of the posterior probability.

Our main focus is on the fiscal multiplier, i.e. the ratio of output changes to the total stimulus-planned change in spending and transfers. Note that due to the eventual balancing of the government budget, there will also be an induced movement in tax rates as a "secondary" effect. As is customary, we shall not include these secondary movements in the denominator, i.e. in quantifying the stimulus-planned changes. As this is a dynamic model, the horizon plays a role. Following Uhlig (2010b), we use the net present value fiscal multiplier $\varphi_{t}$, dividing the net present value of output changes up to

\footnotetext{
${ }^{1}$ Details of the estimation are available in table 12 and figure 20 in the technical appendix
} 


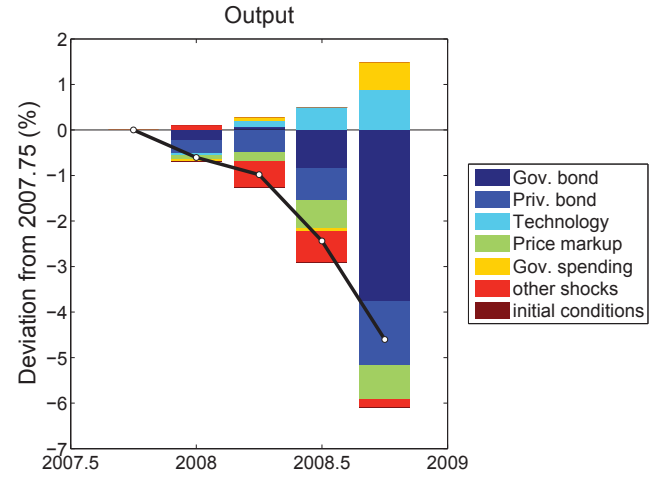

Figure 3: Historical Shock Decomposition: Output. Results are at the posterior median. 200\%:4 is the NBER recession date.

Table 2: Historical decomposition of recent recession and overall variance decomposition for output. All numbers are at the Bayesian posterior mean.

\begin{tabular}{|c|c|c|c|}
\hline Shock & $\begin{array}{l}2 \\
\text { Histo } \\
\text { total }\end{array}$ & $\begin{array}{l}\text { is. } 2007: 4 \\
\text { ecomposition } \\
\text { percent }\end{array}$ & $\begin{array}{c}\text { Total Sample } \\
\text { Variance decomposition } \\
\text { percent }\end{array}$ \\
\hline Gov. bond & -3.76 & 81.69 & 5.11 \\
\hline Priv. bond & -1.41 & 30.63 & 1.38 \\
\hline Technology & 0.89 & -19.44 & 19.23 \\
\hline Price markup & -0.74 & 16.14 & 6.68 \\
\hline Gov. spending & 0.60 & -12.95 & 3.49 \\
\hline Priv. inv. & -0.30 & 6.57 & 14.04 \\
\hline Labor tax & -0.26 & 5.60 & 19.63 \\
\hline Monetary pol. & 0.22 & -4.69 & 17.37 \\
\hline Wage Markup & 0.14 & -3.11 & 8.38 \\
\hline Gov. inv. & 0.03 & -0.65 & 4.59 \\
\hline Initial Values & -0.01 & 0.22 & $\mathrm{n} / \mathrm{a}$ \\
\hline Sum & -4.60 & 100.00 & 100.00 \\
\hline
\end{tabular}




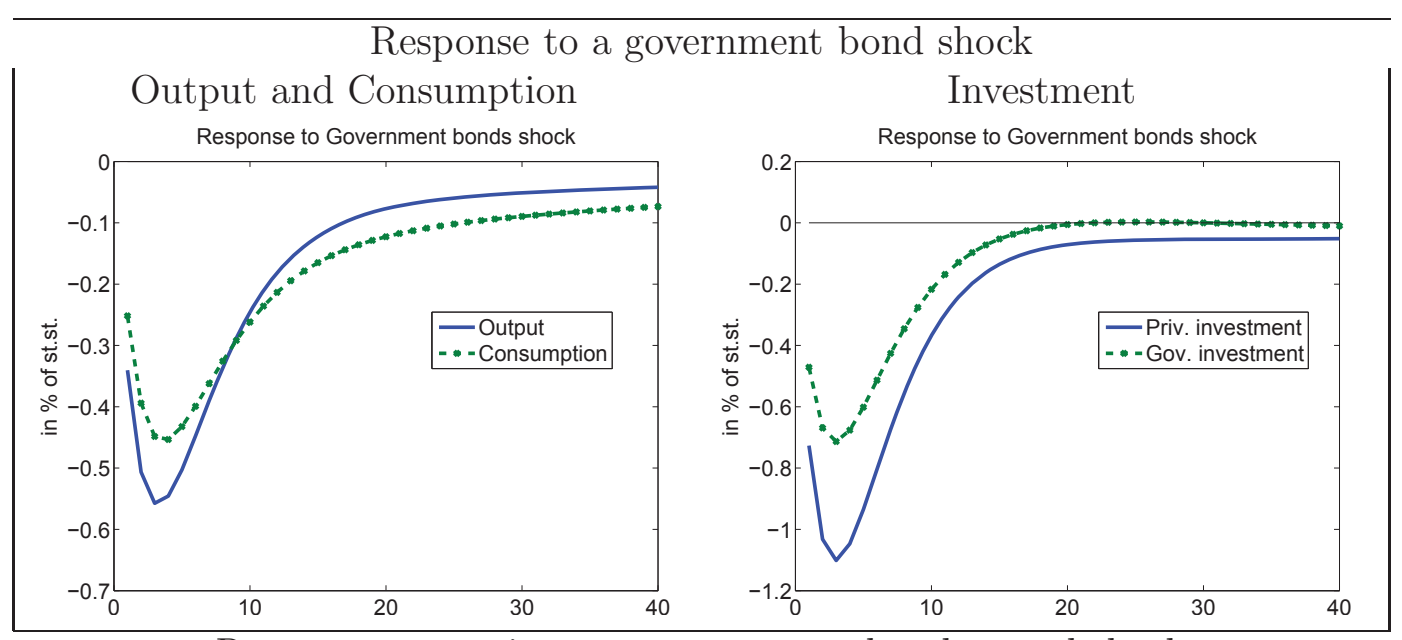

Response to a private-vs-government bond spread shock Output and Consumption
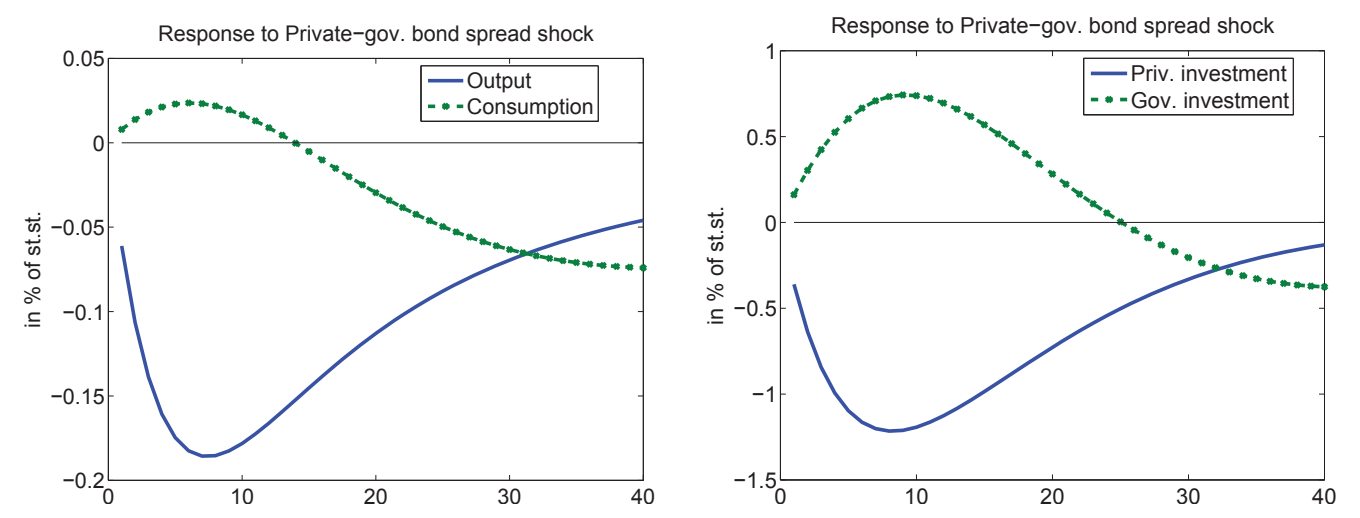

Figure 4: Response to the bond shocks 
some horizon $t$ by the change in government spending and transfers until the same time. I.e., we shall use

$$
\varphi_{t}=\sum_{s=1}^{t}\left(\mu^{s} \prod_{j=1}^{s} R_{j, A R R A}^{-1}\right) \hat{y}_{s} / \sum_{s=1}^{t}\left(\mu^{s} \prod_{j=1}^{s} R_{j, A R R A}^{-1}\right) \hat{g}_{s}
$$

where $\varphi_{t}$ : horizon-t multiplier, $R_{j, A R R A}$ is the government bond return, from $j-1$ to $j, \hat{y}_{s}$ is the output change at date $s$ due to ARRA in percent of the balanced-growth GDP path and $\hat{g}_{s}$ : ARRA spending at date $s$ in percent of the balanced-growth GDP path.

\subsection{Benchmark results}

Figure 5 contains our benchmark results for output, the unemployment rate, the federal funds rate, inflation, government debt, and consumption. ${ }^{2}$ These graphs are perhaps reminiscent of the information shown in the official White House piece by Bernstein and Romer (2009). However, we include an important piece of information, which is missing there. The short-run debt dynamics shown here induce a long-run debt-and-tax dynamics, shown in figure 6 . The increase in labor tax rates long after the fiscal stimulus phase has finished induces the decline of output for many years to come.

The resulting fiscal multiplier will therefore decline with the horizon. The fiscal multipliers for the shorter horizon, shown in the left panel of figure 7 can therefore be quite misleading in terms of assessing the long-term costs of fiscal stimulus. Indeed, the long-run multipliers are considerably smaller or negative, compared to the short-run multipliers, as show in the right panel of figure 7. These results are qualitatively in line with Uhlig (2010b), though the results are quantitatively rather different: the long-run fiscal multipliers are negative there and here, but considerably more negative there. One may be tempted to read the difference as "relief" compared to the pessimistic scenario in Uhlig (2010b). Note, however, that the model here is heavily

\footnotetext{
2 Results for the consumption of both types of agents, real wages, tax rates, and investment are shown in Figure 15.
} 


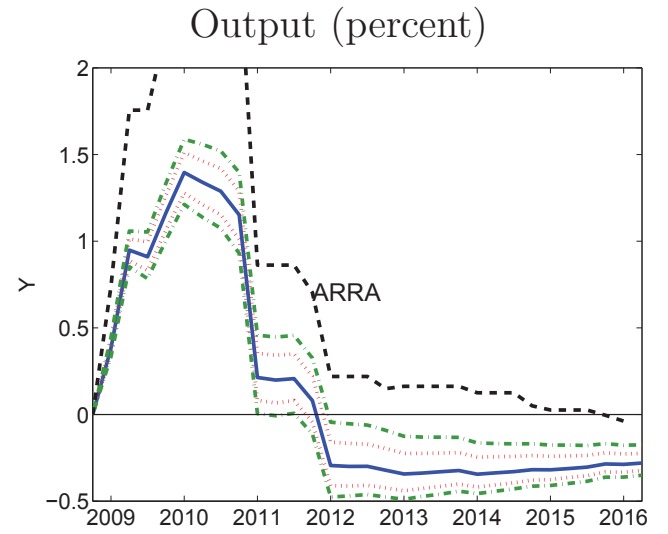

FFR (percent at quarterly rate)
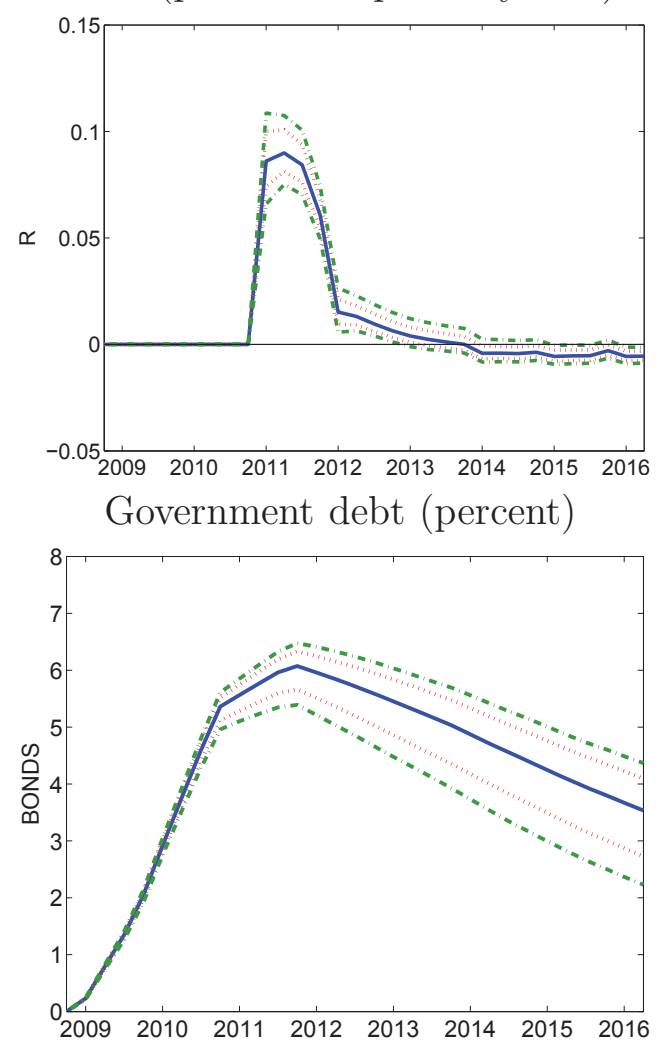

Unemployment rate (percentage points)

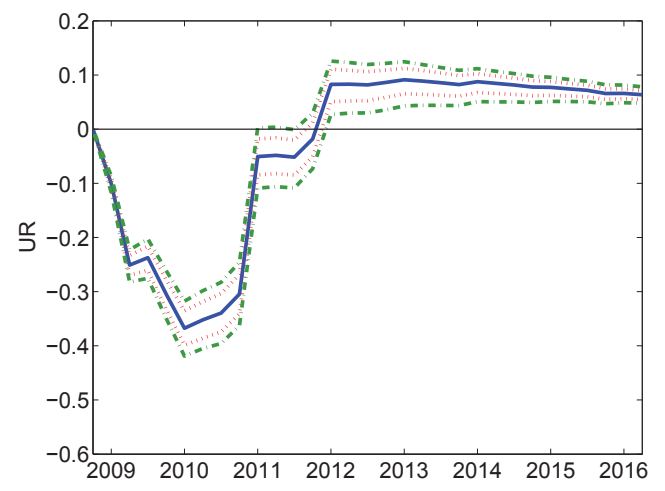

Inflation (percent at quarterly rate)

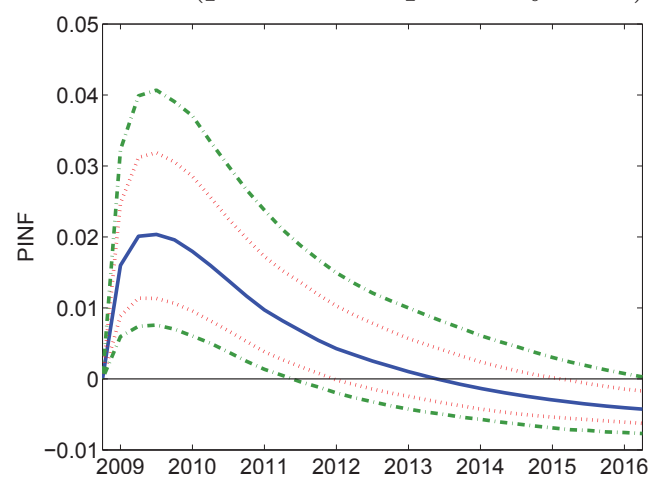

Aggregate Consumption (percent)

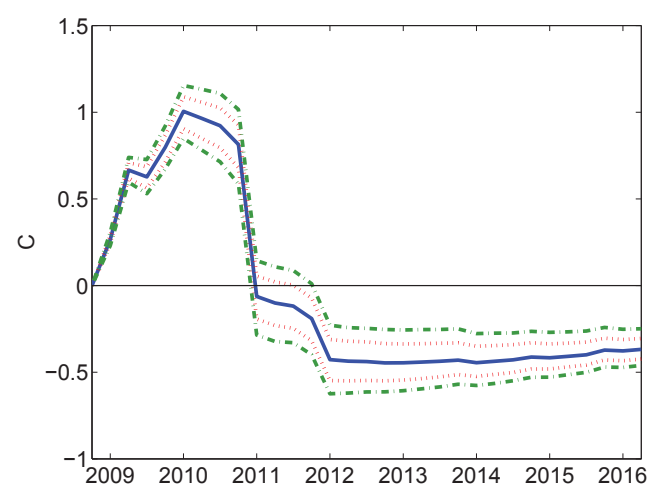

Figure 5: Benchmark impact of ARRA. 
short-run:

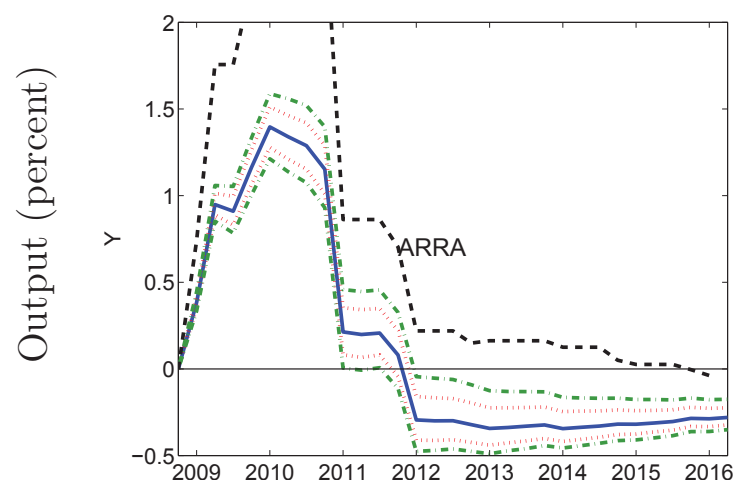

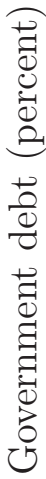

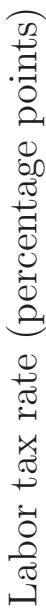

long-run:
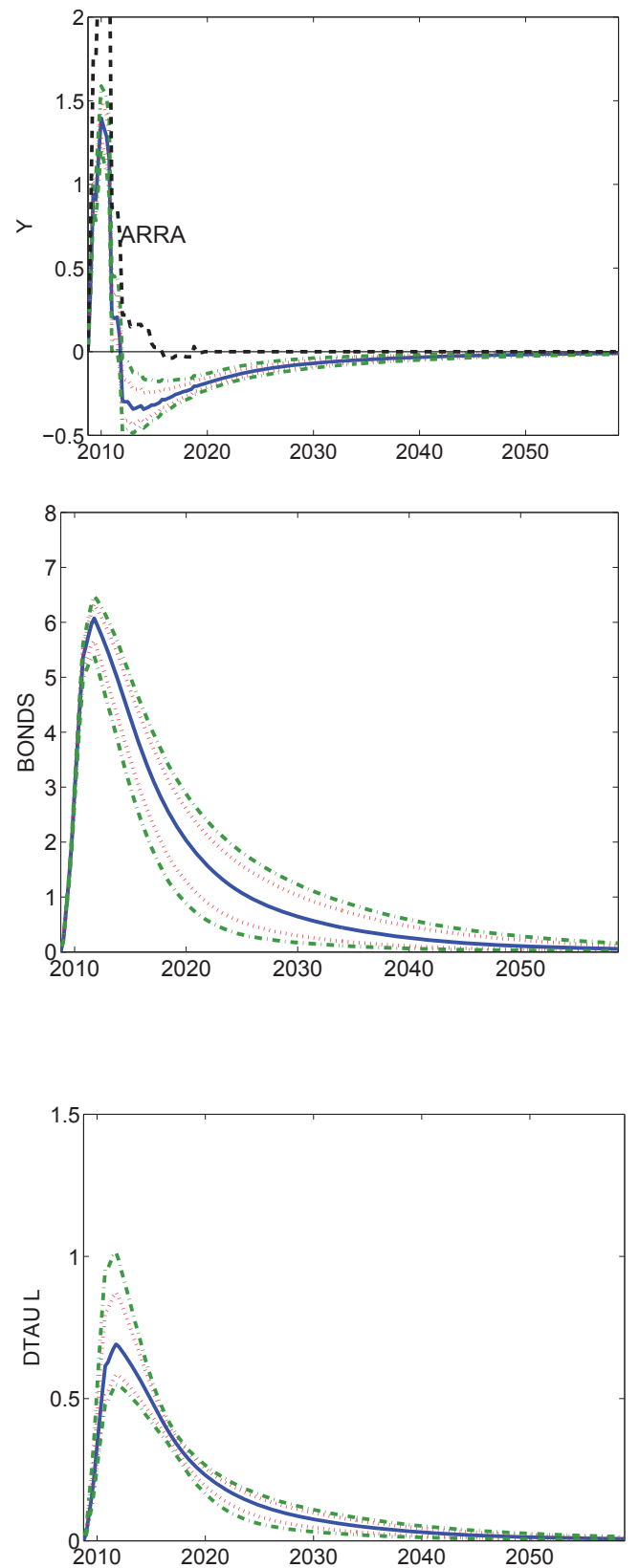

Figure 6: Short- and long-run impact of ARRA. 
tilted towards a model in which fiscal stimulus is often thought to work well: we therefore believe that the negative long-run effects of fiscal stimulus should give pause to arguments in its favor. Even at the short horizon, the benchmark multiplier is just around 0.5.

\subsection{Sensitivity analysis: overview}

Which features of the model contribute to the size of the fiscal multipliers, which are particularly important? Where does the difference to Uhlig (2010b) come from? Understanding the differences and understanding the sensitivity of the benchmark results to key assumptions is important. Figure 8 as well as table 3 and table 4 provide an overview of our sensitivity analysis. The next subsections provide the details.

\subsection{Sensitivity to distortionary taxation}

Along with Uhlig (2010b), we emphasize the importance of assuming distortionary rather than lump-sum taxes in this analysis. Figure 9 provides a comparison. As should be clear, distortionary rather than lump-sum taxation makes a considerable difference and creates significantly lower long-run multipliers, whereas the short-run multipliers are not significantly different. Adjusting consumption taxes only yields a slightly higher multiplier than adjusting labor tax rates.

Note that the dramatic difference due to distortionary taxation is not an artefact of the stimulus being spread out over time. To illustrate this, we consider the case when the entire stimulus is spent uniformly over the first four quarters and compute the multiplier for two cases: when lump-sum transfers are adjusted and when distortionary labor taxes are adjusted. Figure 3.3 shows a large difference. When transfers are adjusted, the multiplier is large and in excess of one, whereas the median multiplier with distortionary taxes declines to almost minus one in the long run. 
Short-run

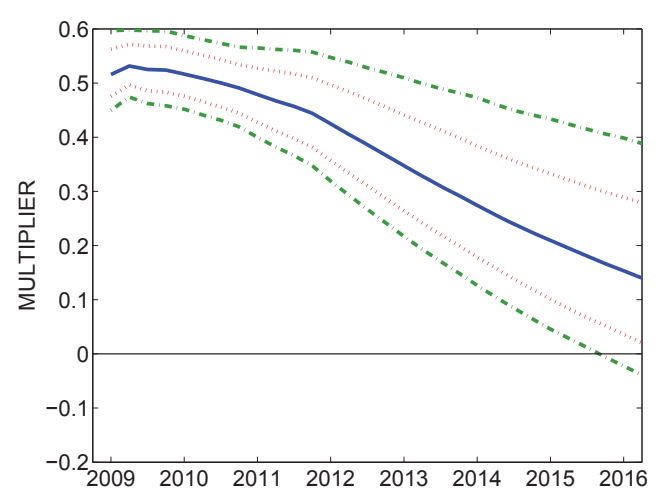

Long-run

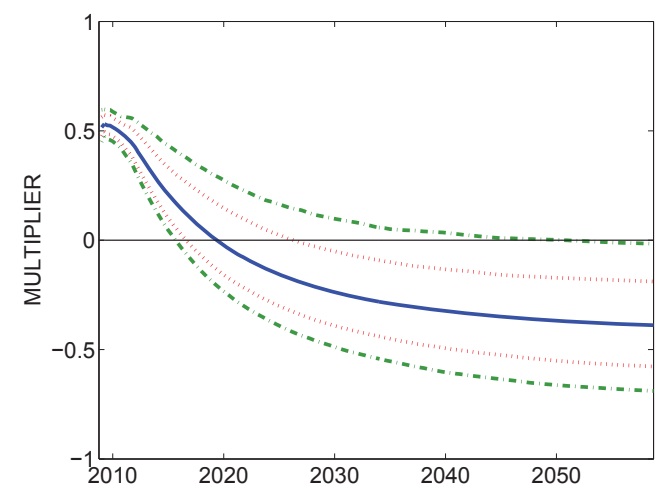

Figure 7: Short-run and long-run fiscal multipliers in the benchmark parameterization.

Complete stimulus, different scenarios Benchmark scenarios, stimulus components separate
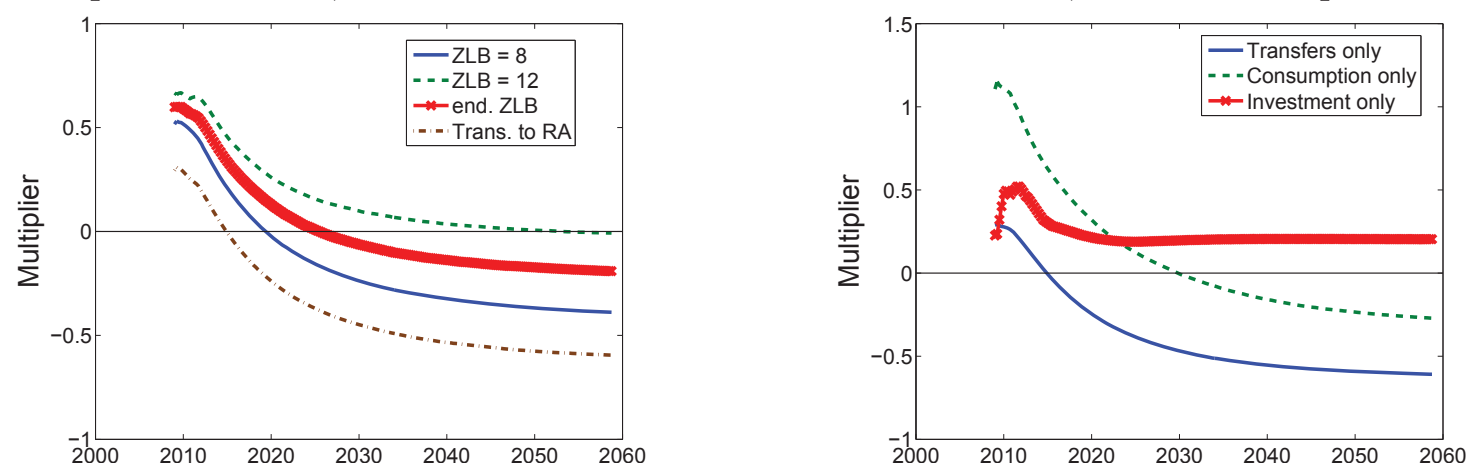

Figure 8: Comparison of long-run multipliers: medians of posterior distributions. 
Table 3: Long run fiscal multipliers as $t \rightarrow \infty$ : sensitivity

\begin{tabular}{c|cc|c|cc}
\hline \hline Scenario & 5 percent & 16.5 percent & median & 83.5 percent & 95 percent \\
\hline Benchmark & -0.72 & -0.61 & -0.42 & -0.22 & -0.04 \\
\hline lump-sum taxes & 0.34 & 0.44 & 0.60 & 0.78 & 0.94 \\
consumption taxes & -0.48 & -0.38 & -0.20 & -0.02 & 0.14 \\
\hline ZLB: 0 Quart. & -1.30 & -1.18 & -1.03 & -0.87 & -0.73 \\
ZLB: 12 Quart. & -0.45 & -0.31 & -0.03 & 0.27 & 0.52 \\
ZLB: Endogenous & -0.56 & -0.43 & -0.19 & 0.14 & 0.57 \\
\hline RoT $=0.15$ & -0.91 & -0.79 & -0.63 & -0.43 & -0.26 \\
RoT=0.35 & -0.59 & -0.44 & -0.24 & -0.04 & 0.18 \\
\hline Share transfers to RoT $=0.00$ & -0.86 & -0.77 & -0.65 & -0.52 & -0.42 \\
Share transfers to RoT $=0.50$ & -0.64 & -0.50 & -0.24 & 0.03 & 0.29 \\
Share transfers to RoT $=1.00$ & -0.50 & -0.28 & 0.16 & 0.64 & 1.05 \\
\hline Priv. capital share=0.35 & -1.13 & -0.98 & -0.76 & -0.51 & -0.27 \\
\hline price/wage-stickiness $=0.10 \times$ estim. & -0.96 & -0.87 & -0.75 & -0.62 & -0.52 \\
price/wage-stickiness $=0.50 \times$ estim. & -0.78 & -0.69 & -0.58 & -0.46 & -0.37 \\
price/wage-stickiness $=1.15 \times$ estim. & -0.91 & -0.76 & -0.56 & -0.33 & -0.12 \\
\hline Budget balance: $\psi_{\tau}=0.025$ & -0.70 & -0.58 & -0.40 & -0.21 & -0.04 \\
Budget balance: $\psi_{\tau}=0.05$ & -0.77 & -0.66 & -0.49 & -0.30 & -0.13 \\
\hline
\end{tabular}

Table 4: One-year fiscal multipliers: sensitivity

\begin{tabular}{c|cc|c|cc}
\hline \hline Scenario & 5 percent & 16.5 percent & median & 83.5 percent & 95 percent \\
\hline Scenario & $5 \%$ & $16.5 \%$ & median & $83.5 \%$ & $95 \%$ \\
\hline Benchmark & 0.46 & 0.48 & 0.52 & 0.57 & 0.60 \\
\hline lump-sum taxes & 0.55 & 0.57 & 0.61 & 0.66 & 0.70 \\
consumption taxes & 0.48 & 0.50 & 0.54 & 0.58 & 0.61 \\
\hline ZLB: 0 Quart. & 0.17 & 0.20 & 0.23 & 0.27 & 0.30 \\
ZLB: 12 Quart. & 0.75 & 0.78 & 0.84 & 0.93 & 1.02 \\
ZLB: Endogenous & 0.51 & 0.54 & 0.60 & 0.69 & 0.78 \\
\hline RoT $=0.15$ & 0.39 & 0.42 & 0.46 & 0.49 & 0.52 \\
RoT $=0.35$ & 0.47 & 0.54 & 0.59 & 0.64 & 0.69 \\
\hline Share transfers to RoT $=0.00$ & 0.25 & 0.26 & 0.29 & 0.31 & 0.33 \\
Share transfers to RoT $=0.50$ & 0.65 & 0.69 & 0.75 & 0.81 & 0.85 \\
Share transfers to RoT $=1.00$ & 1.05 & 1.11 & 1.21 & 1.32 & 1.39 \\
\hline Priv. capital share $=0.35$ & 0.44 & 0.47 & 0.52 & 0.57 & 0.61 \\
\hline price/wage-stickiness $=0.10 \times$ estim. & 0.05 & 0.07 & 0.11 & 0.14 & 0.16 \\
price/wage-stickiness $=0.50 \times$ estim. & 0.35 & 0.38 & 0.42 & 0.47 & 0.50 \\
price/wage-stickiness $=1.15 \times$ estim. & 0.44 & 0.46 & 0.50 & 0.53 & 0.56 \\
\hline Budget balance: $\psi_{\tau}=0.025$ & 0.48 & 0.51 & 0.54 & 0.58 & 0.61 \\
Budget balance: $\psi_{\tau}=0.05$ & 0.43 & 0.46 & 0.49 & 0.53 & 0.56 \\
\hline
\end{tabular}



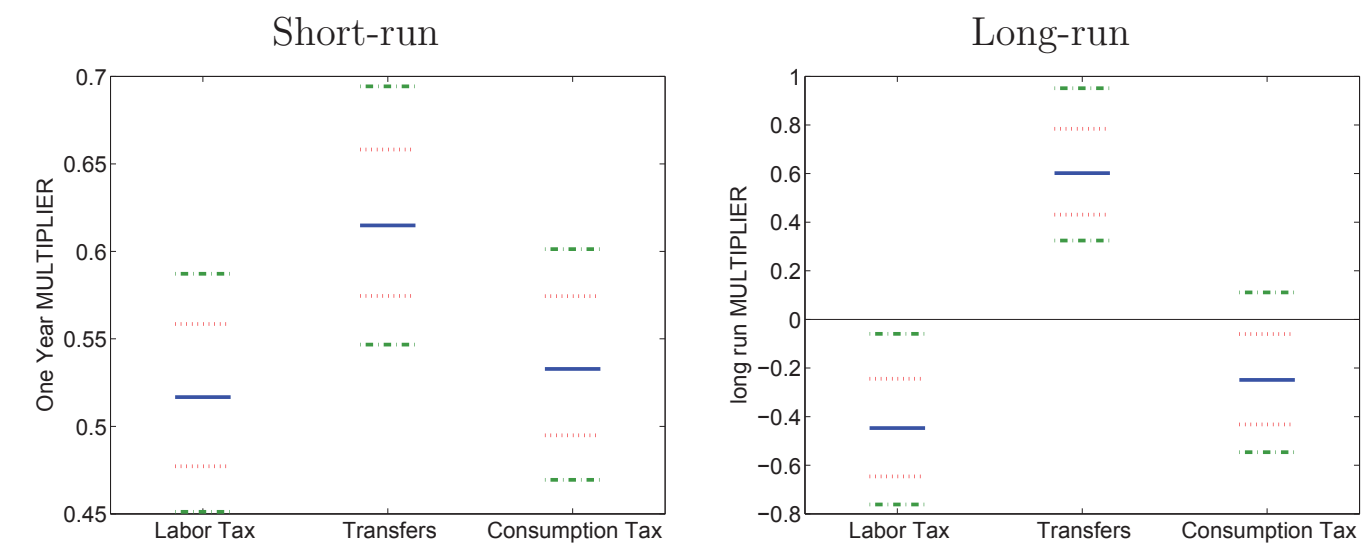

Figure 9: Fiscal multipliers. Comparing distortionary labor taxes (benchmark) to consumption and lump-sum taxation.
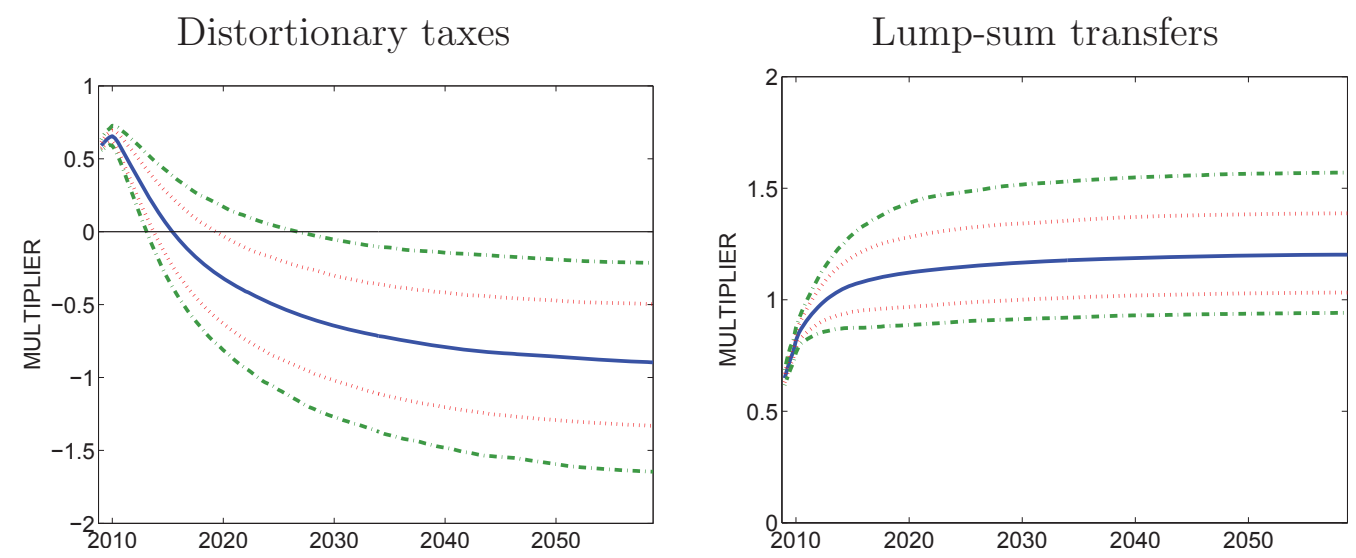

Figure 10: Fiscal multipliers. Stimulus spend uniformly over first four quarters. Comparing distortionary labor taxes (benchmark) lump-sum taxation. 
Within the range of stable parameter values, increasing the speed at which the budget is balanced $\psi_{\tau}$ leads to lower multipliers as shown in tables 3 on page 25 and 4 on page $25 .^{3}$

\subsection{Sensitivity to the length zero lower bound}

The literature has emphasized the sensitivity of fiscal multipliers to the zero lower bound, and to generating "fiscal stimulus", while the central bank is not changing its interest rates, see Eggertsson (2010) as well as Christiano et al. (2009). Our benchmark has been set to 8 quarters, implying that at the beginning of 2009, households anticipated the zero lower bound constraint to no longer bind at the beginning of 2011. That time horizon seems to have been extended meanwhile. However, it is hard to argue that this was anticipated two years ago. Nonetheless, we provide some experimentation here. Figure 11 provides that sensitivity analysis. It shows that when we endogenize the ZLB, the resulting multipliers are comparable since a successful stimulus shortens the ZLB and thereby reduces its effectiveness, even though the expected duration is longer. With an endogenous ZLB or a deterministic duration of twelve quarters, the long-run multipliers are centered at -0.19 and $-0.03 .{ }^{4}$

\subsection{Sensitivity to credit-constrained households}

The "credit-contrained" or "rule-of-thumb" households are important in two respects. First, there is a sizeable portion of the population which violates Ricardian equivalence. Second, the split of transfers between these households and the unconstrained households leads to distributional and thereby aggregate consequences. It turns out that the second effect is more important than the first.

\footnotetext{
${ }^{3}$ Note that the habit formation prevents us from examining significantly higher speeds of budget balance. In the absence of habit formation, $\psi_{\tau}=1$ is consistent with a locally unique equilibrium.

${ }^{4}$ Figure 17 in the technical appendix shows that with an endogenous ZLB only about $10 \%$ of all simulations results in an ZLB exceeding three years.
} 

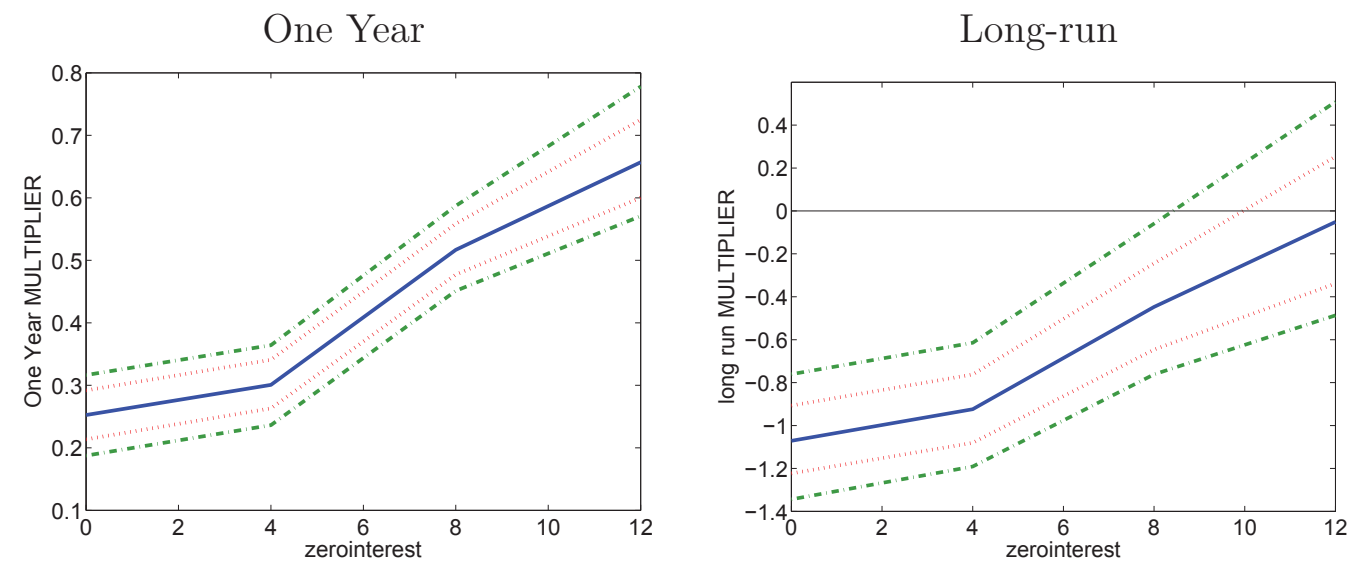

Figure 11: Short-run and long-run fiscal multipliers: sensitivity to the length of the zero lower bound.

The first row of table 5 shows the change in the fiscal multipliers, when we change the share of the population which is credit-constrained. In this experiment, the transfers are equally distributed across the population, i.e., the share of the transfers to the credit-constrained population equals the share of that population. This confounds two effects, however. The first is the mere rise in the share of credit-constrained households, but leaving their share of transfer receipts the same: this is shown in the second row of table 5. The second is the share of transfers received by the credit-constrained households. The third row of table 5 therefore varies the share of transfers received by these households, but keeping their share of the population constant at the benchmark value of 25 percent. While the second experiment has a rather modest impact on the short-run multiplier, the last experiment has a larger impact there. The long-run multipliers move considerably for both experiments. For example and for the last experiment, the median estimate, the long-run fiscal multiplier changes from -0.51 to 0.29 , as that fraction is varied from zero to 100 percent.

One may wish to conclude from this that "fiscal stimulus" in the form of transfers to constrained agents may be quite effective in increasing output. That may be so. However, the modeling of the credit-constrained agents is done here with the simple short-cut of assuming that these agents do not keep 
savings and cannot borrow. For a more sophisticated exercise, the bounds to borrowing and savings should be endogenized, and may actually depend on the size of the government transfers. Furthermore, micro data can potentially be informative about the degree to which households are credit-constrained or refrain from saving. A deeper investigation into the details is called for, if "fiscal stimulus" programs in the future are to focus on this particular group.

\subsection{Sensitivity to the composition of the stimulus}

We departed from the original Smets-Wouters model in order to model the fiscal stimulus in more detail by being able to distinguish between money spend on government transfers, consumption, and investment. In our model, each component has a different impact on the economy. As discussed above, who receives the transfers is an important question. Since constrained households spend all their income, transfers to them are closer to direct government spending. Discretionary government investment increases private sector productivity, but may also crowd out optimal government investment, thereby effectively lowering the size of the long-term debt burden faced by households. The right panel in Figure 8 shows that in our benchmark model, the government investment component contributes to a positive multiplier, whereas the government consumption and transfer components lower the overall multiplier below zero.

\subsection{Sensitivity to the capital share}

The estimated capital share is around 0.24 rather than 0.35 , as often used in the calibration literature, see Cooley and Prescott (1995). The comparisons in figure 12 reveal, that the results are quite sensitive to this parameter, which in our model crucially also governs the tax base for labor taxes. 
Table 5: Short-run and long-run fiscal multipliers: sensitivity to creditconstrained fraction of the population and their share of transfers. First line: all households receive the same amount of transfers, i.e. fraction of constrained households and total transfers rise together. Second line, only the fraction of constrained household rises. Third line: only the share of transfers going to constrained households rises.

\begin{tabular}{l|ccc|ccc} 
& \multicolumn{3}{|c|}{ one year multiplier } & \multicolumn{3}{c}{ long-run multiplier } \\
\hline Transfers $=$ RoT fraction $=$ & 0.10 & 0.25 & 0.40 & 0.10 & 0.25 & 0.40 \\
Const. transfers $/$ household: & 0.33 & 0.54 & 0.82 & -0.62 & -0.31 & 0.12 \\
\hline Transfers $=0.25$, RoT fraction $=$ & 0.10 & 0.25 & 0.40 & 0.10 & 0.25 & 0.40 \\
Fixed absolute transfers & 0.45 & 0.54 & 0.66 & -0.53 & -0.31 & -0.03 \\
\hline RoT Share $=0.25$, Transfers $=$ & 0 & 0.25 & 1.00 & 0 & 0.25 & 1.00 \\
Fixed population share & 0.31 & 0.54 & 1.23 & -0.51 & -0.31 & 0.29 \\
\hline
\end{tabular}

One Year

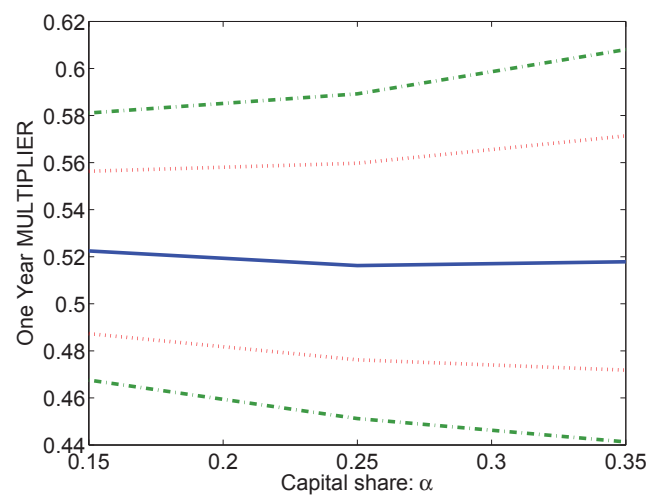

Long-run

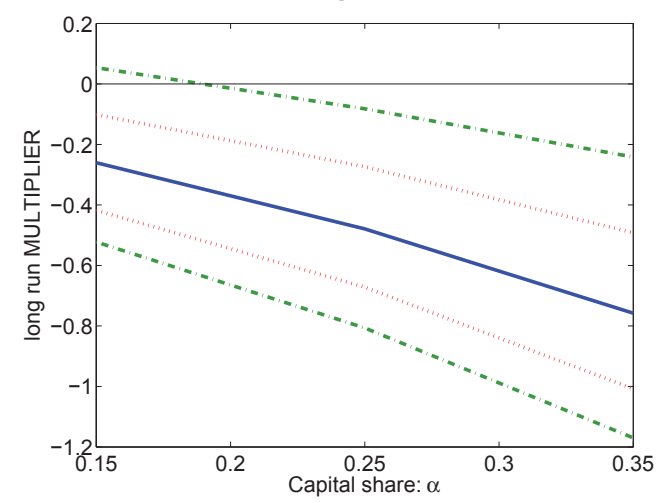

Figure 12: Short-run and long-run fiscal multipliers: sensitivity to the capital share. 

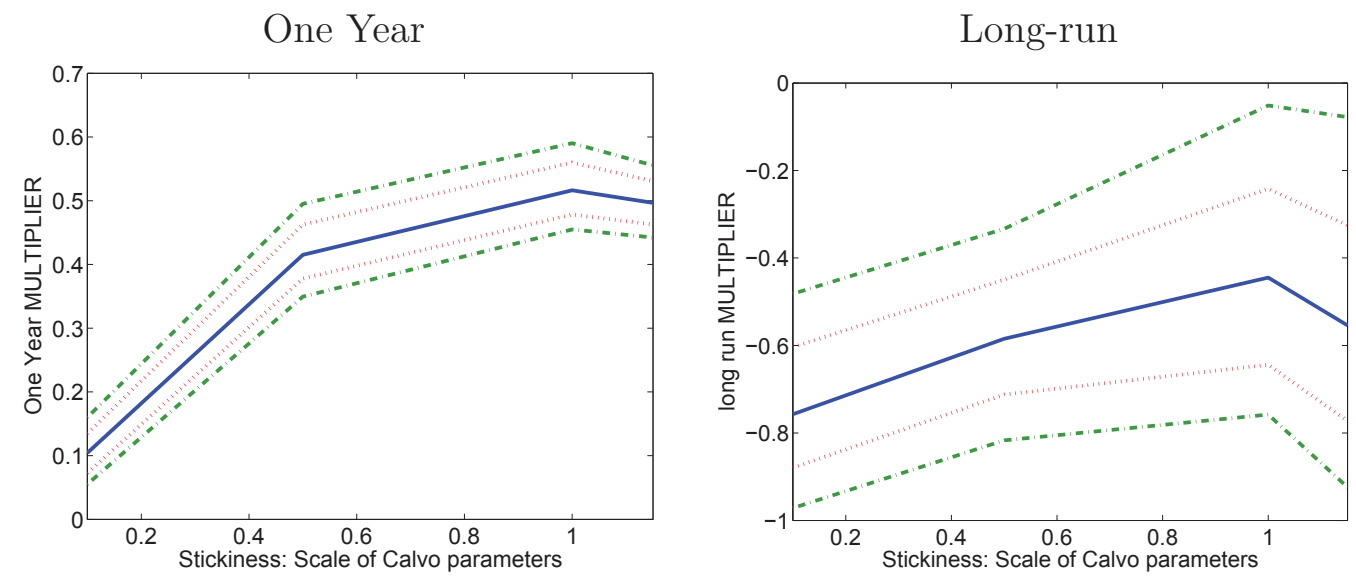

Figure 13: Short-run and long-run fiscal multipliers: sensitivity to price and wage stickiness.

\subsection{Sensitivity to price and wage stickiness}

Finally, it may be interesting to document the impact of the price and wage stickiness on the fiscal multipliers: this is done in figure 13. Note that the median estimates are $\zeta_{p}=0.81$ and $\zeta_{w}=0.83$ for the Calvo parameter for prices and wages. In the figure we consider values of $10 \%$ to $115 \%$ of these median estimates, scaling both parameters proportionately. While the figure mostly shows an increase in the multiplier with increasingly sticky prices and wages, this is no longer true when prices and wages get very sticky. Essentially, at that point, future inflation due to the zero lower bound no longer induces upward pressure on prices and wages, thereby lessening the impact of fiscal stimulus. Reducing the overall stickiness leads to much larger inflation responses (cf. Figure 18 in the technical appendix) and may therefore be more realistic than the estimated stickiness parameters.

\subsection{Welfare effects}

Both the long-run and short-run multiplier are silent on welfare implications of the stimulus package. If the output increase is driven by a disproportionate increase in hours worked, consumers are likely to be worse off even if the multiplier is large and positive. 
Given perfect foresight of the stimulus plan, we can calculate the compensating variation in lifetime consumption along the balanced growth path which makes consumers indifferent between ARRA and the modified historic growth path. Let $\Gamma_{i} \times 100$ be the percentage of consumption without the stimulus, which consumers of type $i, i \in\{R A, R o T\}$ would be willing to give up each period to have the ARRA in place. We provide an explicit formula in a technical appendix. The expressions amount to calculating the net present value of future utility changes. The discount rate for each consumer type enters here in a crucial manner.

Two caveats complicate the welfare calculation. First, the calculation is numerically challenging because at our estimates the effective discount factor $\beta_{R A} \mu^{1-\sigma}$ is close to unity so that convergence is slow. Numerical error is important to address because we are relating the cost of an intervention over about ten years to lifetime consumption so that errors of a small magnitude might be important for the results. Second, our parameter estimates are only directly applicable to unconstrained households, whereas social welfare depends on both types of households. If constrained households are sufficiently impatient and receive a high weight in the social welfare function, the results presented above could be overturned because constrained agent might value the initial consumption increase enough. The calibration of the discount rate for the constrained households is a challenge, however. Lawrance (1991) finds that rates of time preference vary by 7 percent on an annual basis across rich and poor households. Using data on individual choices between lump-sum and annuity payments, Warner and Pleeter (2001) find differences in annual rates of time preference of up to 30 percent, varying by various characteristics. We therefore consider two discount factors for the RoT agents per adding $7 \%$ as well as $30 \%$ to the annual discount factor of the unconstrained agents, i.e.

$$
1 / \beta_{R o T} \in\left\{1 / \beta_{R A}+0.07 / 4,1 / \beta_{R A}+0.3 / 4\right\}
$$

noting that our model is for quarterly data. We also vary over a wider range.

For the unconstrained households, the welfare effects are small but signif- 
icantly negative according to our calculations in Table 6 . The median effect on constrained agents is -0.02 percent, independent of the length of the ZLB with the 90 percent posterior confidence intervals ranging from -0.04 percent to -0.01 percent. The small magnitude is not surprising given that small deviations from the optimum have small effects on welfare of unconstrained agents. Unconstrained agents suffer from an increase in hours worked and for most parameter values considered also from a drop in consumption, explaining the negative sign.

The effect on constrained agents is ambiguous, as lines two and three in table 6 show. If the discount factgor of the RoT agents is just $7 \%$ higher than that of the unconstrained agents, the welfare effect is negative, but it is positive, if their discount factor is $30 \%$ higher. Figure 14 shows the results for a range of discount factor increases, compared to the unconstrained agents. Beyond the threshold of adding 10\%, a higher rate of time preference leads to a more positive evaluation of the stimulus.

\section{Conclusions}

We have quantified the size, uncertainty and sensitivity of fiscal multipliers in response to the American Recovery and Reinvestment Act (ARRA) of 2009. To that end, we have extended the benchmark Smets and Wouters (2007) New Keynesian model, allowing for credit-constrained households, a central bank constrained by the zero lower bound, government capital and a government raising taxes with distortionary taxation. We have distinguished

Table 6: Welfare effects $(\Gamma \times 100)$ of stimulus: Lifetime-consumption equivalent of compensating variation for stimulus. Posterior median (90\% posterior confidence interval).

\begin{tabular}{l|c|cc}
\hline \hline Scenario & 8 quarters ZLB & 0 quarters ZLB & 12 quarters ZLB \\
\hline Unconstrained agents & $-0.02(-0.04,-0.02)$ & $-0.02(-0.04,-0.01)$ & $-0.02(-0.03,-0.02)$ \\
\hline RoT, 7\% higher annual DF & $-0.08(-0.14,-0.02)$ & $-0.15(-0.22,-0.09)$ & $-0.09(-0.17,0.01)$ \\
RoT, 30\% higher annual DF & $0.59(0.35,0.91)$ & $0.44(0.21,0.63)$ & $0.54(0.20,0.92)$ \\
\hline
\end{tabular}


8 qtr. ZLB

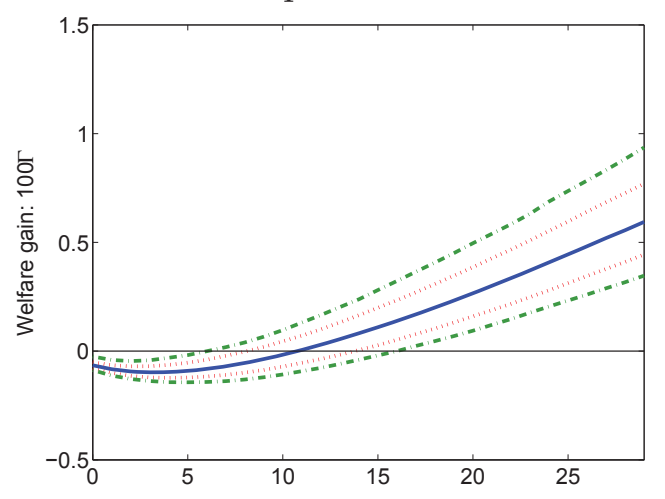

12 qtr. ZLB

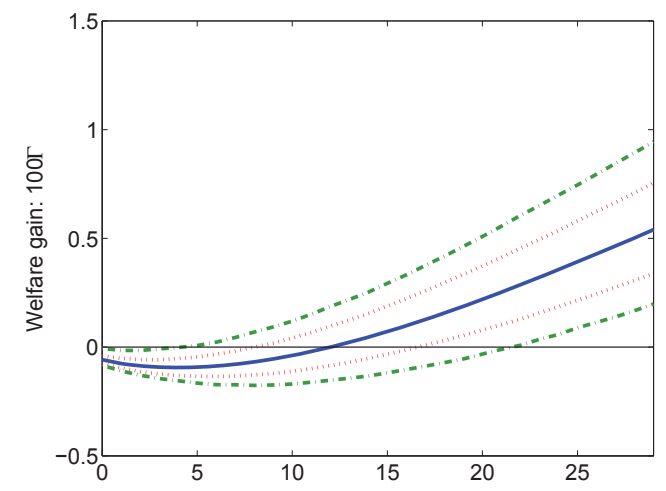

Figure 14: Long-run welfare gains from stimulus: 8 and 12 qtr. ZLB, varying annual rate of time preference compared to unconstrained agents.

between short-run and long-run multipliers. For a benchmark parameterization, we find modestly positive short-run multipliers with a posterior mean of 0.52 and modestly negative long-run multipliers centered around -0.42 . The multiplier is particularly sensitive to the type of taxes used to finance the ARRA, is sensitive to the fraction of transfers given to credit-constrained households, is sensitive to the anticipated length of the zero lower bound, is sensitive to the capital share and is nonlinear in the degree of price and wage stickiness. Reasonable specifications are consistent with substantially negative short-run multipliers within a short time frame. Furthermore, the policy intervention may lower the welfare of agents in the economy: unconstrained agents would have a higher lifetime utility without the ARRA and even impatient constrained agents may be better off without the intervention because of the disutility of hours worked during the expansion and lower consumption in the transition to the long-run offset short-run gains from higher consumption.

\section{References}

Barro, Robert J. and Xavier Sala-i Martin (1992). "Public Finance in Models of Economic Growth". The Review of Economic Studies, 59(4):645-661. 
Bernstein, Jared and Christina Romer (2009). "The Job Impact of the American Recovery and Reinvestment Act". press release, January 9, Office of the Vice President Elect.

Buiter, Willem (2009). "The unfortunate uselessness of most 'state of the art' academic monetary economics". www.voxeu.org, March 6, 2009.

Christiano, Lawrence, Martin Eichenbaum, and Sergio Rebelo (2009). "When is the government spending multiplier large?" draft, Northwestern University.

Coenen, G., C. J. Erceg, C. Freedman, D. Furceri, M. Kumhof, R. Lalonde, J. Linde, D. Muir, S. Mursula, A. Mourougane, J. Roberts, W. Roeger, S. Snudden, M. Trabandt, and J. in’t Veld (2010). "Effects of Fiscal Stimulus in Structural Models". IMF Working Papers 10/73, International Monetary Fund.

Cogan, John F., Tobias Cwik, John B. Taylor, and Volker Wieland (2010). "New Keynesian versus old Keynesian government spending multipliers". Journal of Economic Dynamics and Control, 34(3):281 - 295.

Congressional Budget Office (2009). "Cost estimate for conference agreement for H.R.1." http://www.cbo.gov/ftpdocs/99xx/doc9989/hr1conference.pdf.

Cooley, Thomas F. and Edward C. Prescott (1995). "Economic Growth and Business Cycles". In Cooley, Thomas F. (ed.) "Frontiers of Business Cycle Research", chap. 1, 1-38. Princeton University Press.

Correia, Isabel, Emmanuel Fahri, Juan Pablo Nicolini, and Pedro Teles (2010). "Unconventional Fiscal Policy at the Zero Bound". draft, Banco de Portugal.

Davig, Troy and Eric M. Leeper (2009). "Monetary-Fiscal Policy Interactions and Fiscal Stimulus". NBER Working Papers 15133, National Bureau of Economic Research. 
Drautzburg, Thorsten and Harald Uhlig (2011). "Zero Lower Bound Dynamics". draft, University of Chicago.

Eggertsson, Gauti B. (2010). "The Paradox of Toil" . draft, Federal Reserve Bank of New York.

Eichenbaum, Martin and Jonas D.M. Fisher (2007). "Estimating the frequency of price re-optimization in Calvo-style models". Journal of Monetary Economics, 54(7):2032-2047.

Erceg, Christopher J. and Jesper Linde (2010). "Is There a Fiscal Free Lunch in a Liquidity Trap?" CEPR Discussion Paper 7624.

Hall, Robert (2010). "The Long Slump". draft, Stanford University.

Ilut, Cosmin and Martin Schneider (2011). "Ambiguous Business Cycles". draft, Duke University.

Juillard, Michel (1996). "Dynare: A program for the resolution and simulation of dynamic models with forward variables through the use of a relaxation algorithm". CEPREMAP, Couverture Orange 9602.

Krugman, Paul (2009). "How Did Economists Get It So Wrong?" New York Times, September 2, 2009.

Lawrance, Emily C (1991). "Poverty and the Rate of Time Preference: Evidence from Panel Data". Journal of Political Economy, 99(1):54-77.

Leeper, Eric M., Michael Plante, and Nora Traum (2010). "Dynamics of fiscal financing in the United States". Journal of Econometrics, 156(2):304-321.

Leeper, Eric M., Nora Traum, and Todd B. Walker (2011). "Clearing up the Fiscal Multiplier Morass: A Bayesian Perspective". Draft, University of Indiana.

Leeper, Eric M., Todd B. Walker, and Shu-Chun Susan Yang (2009). "Government Investment and Fiscal Stimulus in the Short and Long Runs". NBER Working Papers 15153, National Bureau of Economic Research. 
Smets, Frank and Raf Wouters (2003). "An Estimated Dynamic Stochastic General Equilibrium Model of the Euro Area". Journal of the European Economic Association, 1(5):1123-1175.

(2007). "Shocks and Frictions in US Business Cycles: A Bayesian DSGE Approach". The American Economic Review, 97(3):586-606.

Spilimbergo, Antonio, Steve Symansky, Olivier Blanchard, and Carlo Cottarelli (2008). "Fiscal Policy for the Crisis". IMF Staff Position Note $S P N / 08 / 01$.

Trabandt, Mathias and Harald Uhlig (2010). "How far are we from the slippery slope? The Laffer Curve revisited." draft, University of Chicago.

Uhlig, Harald (2010a). "Economics and Reality". Working Paper 16416, National Bureau of Economic Research.

- (2010b). "Some Fiscal Calculus". American Economic Review, Papers and Proceedings, 100:30-34.

Warner, John T. and Saul Pleeter (2001). "The Personal Discount Rate: Evidence from Military Downsizing Programs". American Economic Review, $91(1): 33-53$. 


\section{Appendix}

\section{$5.1 \quad$ Data}

The different series come from the NIPA tables, the FRED 2 database and the Bureau of Labor Statistics (BLS) database. Federal debt data is taken from Dallas Fed database. Nominal series for wages, consumption, government and private investment deflated with general GDP deflator.

Generally we follow Smets and Wouters (2007) when creating our dataset with the following exemptions: we use civilian non-institutionalized population throughout, although the series is not seasonally adjusted before 1976 . The base year for real GDP is 2005 instead of 1996. We include durables consumption in investment instead of consumption. Using the same definition, all series but real wages exhibit a correlation of almost 100 percent across the two datasets. For the change in real wages, the correlation is 0.9. Including durables consumption in investment causes the correlation for the investment series to drop to 0.70 and for consumption to 0.78 .

Since no data for the Corporate-Treasury bond yield spread is available before 1953:1 we set it to zero for the missing periods. We use the secondary market rate for 3-month TBill before 1954:3 as the FFR is not available.

The categorization of the various stimulus components is shown in detail in tables 9, 10 and 11 in the technical appendix. As source, we have used Congressional Budget Office (2009), specifically "Table 2: Estimated cost of the conference agreement for H.R. 1, the American Recovery and Reinvestment Act of 2009, as posted on the website of the House Committee on Rules." The annual time path for these expenditures is taken from Congressional Budget Office (2009) and the annual sum for each component is split across quarters in proportion to the aggregate series in Cogan et al. (2010).

\subsection{Estimation}

Tables 7 and 8 contain the results from estimating our model, using Dynare and a Bayesian prior. 
Table 7: Estimation, part 1. The calibrated government investment-to-GDP ratio as well as the estimated growth trend $\mu$ implies a government share in production of $\zeta=2.30$ percent.

\begin{tabular}{|c|c|c|c|c|}
\hline & Prior & Prior mean (s.d.) & $\begin{array}{c}\text { SW Model } \\
66: 1-08: 4\end{array}$ & $\begin{array}{c}\text { Our Model } \\
49: 2-08: 4\end{array}$ \\
\hline Adj. cost $S^{\prime \prime}(\mu)$ & norm & $4.000(1.500)$ & $5.93(1.1)$ & $4.51(0.78)$ \\
\hline Risk aversion $\sigma$ & norm & $1.500(0.375)$ & $1.42(0.11)$ & $1.17(0.08)$ \\
\hline Habit $h$ & beta & $0.700(0.100)$ & $0.7(0.04)$ & $0.85(0.02)$ \\
\hline Calvo wage $\zeta_{w}$ & beta & $0.500(0.100)$ & $0.77(0.05)$ & $0.83(0.03)$ \\
\hline Inv. labor sup. ela. $\nu$ & norm & $2.000(0.750)$ & $1.96(0.54)$ & $2.16(0.51)$ \\
\hline Calvo prices $\zeta_{p}$ & beta & $0.500(0.100)$ & $0.69(0.05)$ & $0.81(0.03)$ \\
\hline Wage indexation $\iota_{w}$ & beta & $0.500(0.150)$ & $0.62(0.1)$ & $0.41(0.08)$ \\
\hline Price indexation $\iota_{p}$ & beta & $0.500(0.150)$ & $0.26(0.08)$ & $0.28(0.07)$ \\
\hline Capacity util. & beta & $0.500(0.150)$ & $0.59(0.1)$ & $0.43(0.07)$ \\
\hline $1+\frac{\text { Fix. cost }}{Y}=1+\lambda_{p}$ & norm & $1.250(0.125)$ & $1.64(0.08)$ & $1.94(0.05)$ \\
\hline Taylor rule infl. $\psi_{1}$ & norm & $1.500(0.250)$ & $2(0.17)$ & $1.63(0.18)$ \\
\hline same, smoothing $\rho_{R}$ & beta & $0.750(0.100)$ & $0.82(0.02)$ & $0.92(0.02)$ \\
\hline same, LR gap $\psi_{2}$ & norm & $0.125(0.050)$ & $0.09(0.02)$ & $0.13(0.03)$ \\
\hline same, SR gap $\psi_{3}$ & norm & $0.125(0.050)$ & $0.24(0.03)$ & $0.2(0.02)$ \\
\hline Mean inflation (data) & gamm & $0.625(0.100)$ & $0.76(0.09)$ & $0.58(0.08)$ \\
\hline $100 \times$ time pref. & gamm & $0.250(0.100)$ & $0.16(0.05)$ & $0.12(0.04)$ \\
\hline Mean hours (data) & norm & $0.000(2.000)$ & $1.07(0.95)$ & $0.04(0.69)$ \\
\hline Trend $(\mu-1) * 100$ & norm & $0.400(0.100)$ & $0.43(0.02)$ & $0.48(0.01)$ \\
\hline Capital share $\alpha$ & norm & $0.300(0.050)$ & $0.19(0.02)$ & $0.24(0.01)$ \\
\hline Gov. adj. cost $S_{g}^{\prime \prime}(\mu)$ & norm & $0.000(0.500)$ & $\mathrm{n} / \mathrm{a}$ & $7.11(1.09)$ \\
\hline Budget bal speed $\frac{\psi_{\tau}-0.025}{0.175}$ & beta & $0.25(0.1637)$ & $\mathrm{n} / \mathrm{a}$ & $0.05(0.04)$ \\
\hline Mean gov. debt & norm & $0.000(0.500)$ & $\mathrm{n} / \mathrm{a}$ & $-0.16(0.51)$ \\
\hline Mean bond spread & gamm & $0.500(0.100)$ & $\mathrm{n} / \mathrm{a}$ & $0.47(0.04)$ \\
\hline
\end{tabular}


Table 8: Estimation, part 2

\begin{tabular}{|c|c|c|c|c|}
\hline & Prior & Prior mean (s.d.) & $\begin{array}{l}\text { SW Model } \\
66: 1-08: 4\end{array}$ & $\begin{array}{c}\text { Our Model } \\
49: 2-08: 4\end{array}$ \\
\hline s.d. tech. & invg & $0.100(2.000)$ & $0.46(0.03)$ & $0.47(0.02)$ \\
\hline $\mathrm{AR}(1)$ tech. & beta & $0.500(0.200)$ & $0.95(0.01)$ & $0.95(0.01)$ \\
\hline s.d. bond & invg & $0.100(2.000)$ & $0.24(0.03)$ & $0.95(0.04)$ \\
\hline $\operatorname{AR}(1)$ bond $\rho_{q}$ & beta & $0.500(0.200)$ & $0.27(0.1)$ & $0.67(0.03)$ \\
\hline s.d. gov't & invg & $0.100(2.000)$ & $0.54(0.03)$ & $0.36(0.02)$ \\
\hline $\mathrm{AR}(1)$ gov’t & beta & $0.500(0.200)$ & $0.98(0.01)$ & $0.98(0.01)$ \\
\hline Cov(gov't, tech.) & norm & $0.500(0.250)$ & $0.53(0.09)$ & $0.3(0.04)$ \\
\hline s.d. inv. price & invg & $0.100(2.000)$ & $0.43(0.04)$ & $1.25(0.1)$ \\
\hline $\mathrm{AR}(1)$ inv price & beta & $0.500(0.200)$ & $0.73(0.06)$ & $0.56(0.06)$ \\
\hline s.d. mon. pol. & invg & $0.100(2.000)$ & $0.24(0.02)$ & $0.22(0.01)$ \\
\hline $\mathrm{AR}(1)$ mon. pol. & beta & $0.500(0.200)$ & $0.16(0.07)$ & $0.22(0.05)$ \\
\hline s.d. goods m-up & invg & $0.100(2.000)$ & $0.14(0.01)$ & $0.32(0.02)$ \\
\hline $\mathrm{AR}(1)$ goods m-up & beta & $0.500(0.200)$ & $0.89(0.04)$ & $0.91(0.05)$ \\
\hline MA(1) goods m-up & beta & $0.500(0.200)$ & $0.73(0.08)$ & $0.96(0.02)$ \\
\hline s.d. wage m-up & invg & $0.100(2.000)$ & $0.26(0.02)$ & $0.23(0.02)$ \\
\hline $\operatorname{AR}(1)$ wage m-up & beta & $0.500(0.200)$ & $0.97(0.01)$ & $0.97(0.01)$ \\
\hline MA(1) wage m-up & beta & $0.500(0.200)$ & $0.91(0.03)$ & $0.92(0.02)$ \\
\hline s.d. Tax shock & invg & $0.100(2.000)$ & $\mathrm{n} / \mathrm{a}$ & $1.44(0.08)$ \\
\hline $\mathrm{AR}(1)$ tax shock & beta & $0.500(0.200)$ & $\mathrm{n} / \mathrm{a}$ & $0.98(0.01)$ \\
\hline s.d. gov. inv. price & invg & $0.100(2.000)$ & $\mathrm{n} / \mathrm{a}$ & $0.79(0.08)$ \\
\hline $\mathrm{AR}(1)$ gov. inv. price & beta & $0.500(0.200)$ & $\mathrm{n} / \mathrm{a}$ & $0.97(0.01)$ \\
\hline s.d. bond spread & invg & $0.100(2.000)$ & $\mathrm{n} / \mathrm{a}$ & $0.08(0)$ \\
\hline $\mathrm{AR}(1)$ bond spread & beta & $0.500(0.200)$ & $\mathrm{n} / \mathrm{a}$ & $0.91(0.02)$ \\
\hline
\end{tabular}

